\title{
Histone H4K20 methylation synchronizes cytoskeletal dynamics with cell cycle phases during epidermal differentiation
}

\author{
Alessandro Angerilli ${ }^{1, \#}$, Janet Tait ${ }^{1, \#}$, Julian Berges ${ }^{1,2}$, Irina Shcherbakova ${ }^{1}$, \\ Tamas Schauer ${ }^{3}$, Pawel Smialowski ${ }^{3}$, Ohnmar Hsam ${ }^{1,5}$, Edith Mentele ${ }^{1}$, Dario \\ Nicetto ${ }^{1,6}$, Ralph A.W. Rupp ${ }^{1 *}$ \\ ${ }^{1}$ Department of Molecular Biology, Biomedical Center, Ludwig-Maximilians-Universität München, Planegg- \\ Martinsried, 82152, Germany \\ ${ }^{2}$ Sektion Pädiatrische Pneumologie und Allergologie und Mukoviszidose-Zentrum, Universitäts-Klinikum \\ Heidelberg, Heidelberg, 69120, Germany \\ ${ }^{3}$ Bioinformatics Unit, Biomedical Center, Ludwig-Maximilians-University Munich, 82152 Planegg- \\ Martinsried, Germany \\ ${ }^{4}$ Department of Physiological Genomics, Biomedical Center, Ludwig-Maximilians-Universität München, \\ Planegg-Martinsried, 82152, Germany \\ ${ }^{5}$ Klinik und Poliklinik für Neurologie der Universität Regensburg, Regensburg, 93053, Germany \\ ${ }^{6}$ Ambys Medicines, South San Francisco, CA 94080, USA \\ \# shared first authors \\ * correspondence: ralph.rupp@bmc.med.Imu.de \\ e-Mails contacts: \\ alessandro.angerilli@gmail.com \\ janet.tait@bmc.med.Imu.de \\ julian.berges@med.uni-heidelberg.de \\ Irina.Shcherbakova@med.uni-muenchen.de \\ tamas.schauer@med.uni-muenchen.de \\ ohnmar.hsam@ukr.de \\ edith.mentele@bmc.med.Imu.de \\ dnicetto@ambys.com
}




\section{SUMMARY}

Histone tails are subject to various post-translational modifications, which play a fundamental role in altering chromatin accessibility. Although they are thought to regulate progression through development, the impact of the most abundant histone modification in vertebrates, i.e., histone $\mathrm{H} 4$ lysine 20 dimethylation (H4K20m2), has remained largely elusive. H4K20m2 arises from sequential methylation of new, unmodified histone $\mathrm{H} 4$ proteins, incorporated into chromatin during DNA replication, by the mono-methylating enzyme PR-SET7/KMT5A during G2/M phases, followed by conversion to the dimethylated state by SUV4$20 \mathrm{H} 1$ enzymes in the following $\mathrm{G} 1 / \mathrm{G} 0$ phase. To address its function, we have blocked the deposition of this mark by depleting Xenopus embryos of SUV420H1/H2 methyltransferases, which convert H4K20 monomethylated to di- and tri-methylated states, respectively In the frog larval epidermis this results in a severe loss of cilia in multiciliated cells (MCC), a key component of all mucociliary epithelia. MCC precursor cells are correctly specified and amplify centrioles, but ultimately fail in ciliogenesis due to perturbation of cytoplasmic processes. Genome wide transcriptome profiling reveals that SUV4-20H1/H2 depleted ectodermal Animal Cap explants preferentially down-regulate the expression of several hundred cytoskeleton and cilium related genes as a consequence of persistent H4K20 monomethyl marks on postmitotic chromatin. Further analysis demonstrated that knockdown of SUV4-20H1 alone is sufficient to generate the MCC phenotype and that overexpression of the H4K20m1specific histone demethylase PHF8 rescues the ciliogenic defect in significant, although partial, manner. Taken together, this indicates that the conversion of $\mathrm{H} 4 \mathrm{~K} 20 \mathrm{~m} 1$ to $\mathrm{H} 4 \mathrm{~K} 20 \mathrm{~m} 2$ by SUV4-20H1 is critical to synchronize cytoskeletal dynamics in concert with the cell cycle.

\section{KEYWORDS}

SUV4-20H1/KMT5B, SUV4-20H2/KMT5C, PR-SET8/KMT5A, histone methyltransferase, JmjC-domain containing protein KDM7B/PHF8, histone posttranslational modifications, histone demethylation, epigenetics, Xenopus, 
development, ciliogenesis, multiciliated cell, mucociliary epithelium, MCIDAS, FOXJ1.

\section{INTRODUCTION}

Methylation of histone residues is a major means by which epigenetic regulation of gene expression is achieved. For example, the main repressive epigenetic marks in higher eukaryotes are the trimethylation of histone $\mathrm{H} 3 \mathrm{~K} 9, \mathrm{H} 3 \mathrm{~K} 27$, and H4K20 (Hyun et al, 2017; Saksouk et al, 2014). Usually when a cell enters Sphase, the epigenetic information contained in parental histones is partitioned to the newly duplicated DNA strands, and is effectively diluted through incorporation of via partitioning of old histones and adequate modification of newly incorporated histones (Alabert et al, 2015; Petryk et al, 2018). This is not the case for histone H4K20 mono and di-methylation. In fact, these epigenetic marks are uniquely written in a cell cycle-dependent manner (Beck et al, 2012b; Pesavento et al, 2008). During the S-phase of the cell cycle newly synthesized, unmodified histones are inserted into the nascent chromatin (Scharf et al, 2009). These histones are monomethylated on H4K20 in a genome-wide fashion by PrSet7/Set8, a histone methyltransferase, whose activity is restricted to the G2-M phases of the cell cycle and undergoes proteolytic degradation in G1 (Beck et al, 2012a). After the anaphase, cells enter the G1 phase, when SUV4-20H1 and SUV4-20H2 enzymes convert this modification to the di and tri-methylated state of H4K20, respectively (Schotta et al, 2004). In mice, SUV4-20H1 generates H4K20m2 globally using the monomethylated residue as substrate (Pannetier et al, 2008). In this way during the G1/G0 phase H4K20me1 disappears from the chromatin with exception of some loci where it is shielded by unknown factors (Jorgensen et al, 2013). Remarkably, in both Xenopus tadpoles and mouse cells H4K20me2 covers $\geq 80 \%$ of the $\mathrm{H} 4$ molecules and it is considered to be the most abundant histone modification in vertebrates (Pokrovsky et al, 2020; Popov et al, 2017).

H4K20 methylation states also have distinct functional connotations. In 
mammals, H4K20me1 has demonstrated roles in replication origin firing (Shoaib et al, 2018), guaranteeing genome integrity (Oda et al, 2009), and chromosome condensation (Beck et al., 2012a). H4K20me1 contributes to the downregulation of X-linked genes during dosage compensation in C. elegans (Brej et al., 2018), and in mammalian cells H4K20me1 down-regulates genes associated with cytoskeleton organization and cell adhesion. It has also been shown that converting H4K20me1 into H4K20me2 during the G2/M phase of the cell cycle leads to strong mitotic defects (Julien \& Herr, 2004). However, due to its ubiquity, the specific functions of H4K20me2 remain elusive (Jorgensen et al., 2013). H4K20me3 is a transcriptional repressor. It primarily localizes to centromeres, telomeres and repetitive DNA elements, and it participates in heterochromatin formation by recruiting factors such as cohesins (Hahn et al, 2013).

Here we report that depletion of SUV4-20H enzymes during Xenopus development strongly affects the formation of ciliary axonemes, the major specialized cytoskeleton structure of multiciliated cells (MCCs) on the embryonic epidermis. By taking advantage of embryonic epidermal organoids (Animal Caps) we demonstrate that knocking down the SUV4-20H enzymes negatively affects the expression of hundreds of cilia and cytoskeleton genes with striking specificity. This study shows that such repression is elicited by the high abundance of H4K20me1 on postmitotic chromatin. In wildtype cells this repressive effect is neutralized by conversion to H4K20me2 status through SUV4-20H1. Taken together our data strongly support a model in which H4K20 mono- and di-methylated states are used to equilibrate the cytoskeleton dynamics of proliferating, undifferentiated cells with those of post-mitotic differentiating cells.

\section{RESULTS}




\section{SUV4-20h enzymes are required for differentiation of multiciliated cells in}

\section{Xenopus larval epidermis}

In order to study the function of H4K20 methylation in vivo, we induced protein knockdown (KD) of SUV4-20H enzymes via radial injection of translation blocking antisense Morpholino oligonucleotides (Mo) with established specificity and effectiveness (Nicetto et al, 2013), and investigated the consequences on H4K20 methyl marks (Figure 1A). SUV4-20H2 KD had a stronger effect on H4K20me3 levels than SUV4-20H1 KD, similar to what is observed in mouse, but only the double KD of both enzymes abolished the H4K20me3 mark. This indicates that the function of the two enzymes is partially redundant. Interestingly, upon individual or double KD of the SUV4-20H enzymes we observed a very strong enrichment for H4K20me1, indicating that in Xenopus this histone mark also serves as a substrate for SUV4-20H methyltransferases.

We noticed that SUV4-20H1/H2 double-morphant (dMO) tadpoles failed to exhibit the typical forward-sliding movement over ground, which is caused by the synchronous and directional beating of motile cilia on the larval epidermis. By ejecting an aqueous dye close to the surface of manipulated embryos we found that this liquid flow was strongly impaired in SUV4-20H dMO embryos (Supplementary videos). A reduced flow reflects either a problem with polarization of the cilia stroke direction, which is controlled by the PCP pathway (Mitchell et al, 2009), or a dysfunction of the cilia tufts on the skin surface. To distinguish between these possibilities, we injected embryos unilaterally with control or suv4-20h1/h2 morpholinos and performed whole mount immunostainings against acetylated alpha-tubulin, a major component of ciliary axonemes (Figure 1B-C). The vast majority of SUV4-20H dMOs displayed clearly reduced ciliary signals on their injected side, indicative of a cell-autonomous defect. This phenotype was reproduced with a second pair of suv4-20h1/h2specific Mos (Supplementary material, Figure S1C and D), whose target regions are non-overlapping with that of the first Mo pair (Figure S1E). In addition, cilia tufts were significantly restored by co-injection of morpholino-insensitive Xenopus suv4-20h1/h2 mRNAs, but not by co-injection of lacZ mRNA. We also noticed 
that overexpression of XSUV4-20H proteins alone increased the density of MCCs within the epidermis, while lacZ mRNA had no effect (Figure S1A and B).

To better elucidate the molecular features of this phenotype we performed a cell mosaic analysis by injecting a single ventro-animal blastomere at the 8 cellstage, whose descendants become mostly epidermis, and analysed the consequences by confocal microscopy. The injected cells were lineage-traced by hyls1-GFP mRNA, which encodes a widely conserved protein stably incorporated into the outer centriolar wall (Dammermann et al, 2009). In this way the progeny of the injected blastomere intermingles with the surrounding wt cells and the manipulated MCCs could be identified by GFP-positive basal bodies (BB; Figure $1 D$ and $E$ ). We then harvested the embryos at tailbud stage (NF28), i.e. after formation of the mucociliary epithelium, and stained them for acetylated alphatubulin (cilia), filamentous actin (cell borders/apical actin lattice), and DNA (nucleus). This experiment demonstrated that SUV4-20H1/H2 dMO MCCs are present on the surface of the embryo and produce in deep cytoplasm a large number of centrioles (maturing into ciliogenic basal bodies). This is very similar to wildtype MCCs, which are known to generate $>100$ centrioles at the outer nuclear membrane via the deuterosome pathway (Meunier \& Azimzadeh, 2016). A more detailed comparison with control MO (CoMo) MCCs, however, revealed that the BBs in SUV4-20H1/H2 depleted MCCs tend to clump in deep cytoplasm and were delayed in transport to, and docking at the apical cell membrane (Figure 1, compare optical sections \#s 2-5 in panel D). Notably, most BBs, which had arrived at the cell membrane, still failed to nucleate ciliary axonemes, detailing a nearly complete loss of cilia in many dMO MCCs. In addition, the apical actin lattice, which forms around BBs (Sedzinski et al, 2016), appears much less dense and uniform in SUV4-20H1/H2 dMO MCCs, compared to CoMo MCCs. Together, these observations indicate that SUV4-20H1/H2 depleted MCCs display a differentiation defect that is due to multiple, possibly linked defects in cytoskeleton structures and processes, which are prerequisite for ciliogenesis. The severe reduction in cilia numbers is sufficient to explain the reduced liquid flow observed along the embryonic epidermis. 


\section{SUV4-20H enzymes are epistatic to the genetic program of multiciliogenesis}

The multiciliogenic differentiation program begins when an epidermal stem cell gets specified by Notch/Delta signaling as a multiciliated cell precursor (Brooks \& Wallingford, 2014). Notch regulates in MCC precursors the expression of multicilin/mcidas (mci), a transcriptional coactivator protein, which establishes a core MCC transcriptome of about 1000 genes with help from key downstream transcription factors, such as Foxj1 and RFX2 (Quigley \& Kintner, 2017). We therefore wondered, whether the effect of SUV4-20H1/H2 depletion on ciliogenesis could be overcome by $\mathrm{MCl}$ overexpression. We addressed this question in mosaic embryos, co-injecting morpholinos and hyls1-GFP transcripts with synthetic mRNA of a hormone-inducible MCI-GR fusion construct. We administered dexamethasone at late gastrula stage (NF12, i.e., when the endogenous mci gene gets activated) and harvested the embryos at late tailbud stage (NF28). In control embryos, MCl-GR induced both de novo amplification of centriole numbers and formation of cilia even in non-ciliated goblet cells, unambiguous evidence for an $\mathrm{MCl}$ gain of function phenotype (Figure S2A). In SUV4-20H1/H2 dMO embryos, however, MCl-GR failed to restore the apical Actin cap as well as ciliary axonemes (Figure S2 A-C).

To exclude the possibility that $\mathrm{MCl}$ could be limited in its function to activate Foxj1, a transcription factor required to produce motile cilia nucleated from the mother centriole of cells (Walentek et al, 2015), we also overexpressed this transcription factor in the dMO condition. As shown in Figure S2, panels D-F, the enhanced levels of Foxj1 were sufficient to induce axoneme formation in CoMo goblet cells, but could not increase cilia numbers in dMO MCCs. Taken together, these results indicate that SUV4- $20 \mathrm{H} 1 / \mathrm{H} 2$ enzymes regulate multiciliogenesis upstream of, or independently from mci and foxj1. This suggests a dominant role for adequate H4K20 methylation levels in chromatin for the assembly of motile cilia tufts at the apical surface of epidermal MCCs. 


\section{SUV4-20H1/H2 dependent transcriptional profile of Xenopus epidermis}

To analyse the changes in gene expression associated with the $\mathrm{dMO}$ epidermal cells, we decided to take advantage of the Animal Cap (AC) organoid system. ACs are prospective ectodermal explants that recapitulate the differentiation of the embryonic epidermis (Angerilli et al, 2018). We injected embryos radially at the 2-cell stage with either control or suv4-20h1/h2 Mos. We then cut ACs at the blastula stage and performed RNA-Seq analysis at three key developmental stages (gastrula, neurula and tailbud; see (Angerilli et al., 2018)) in three biological replicates, obtaining approximately 100 million reads per stage. For gastrula stage ACs differential gene expression analysis revealed only 30 genes to be misregulated between CoMo and $\mathrm{dMO}$ conditions (23 upregulated, 7 downregulated). At the tailbud stage, we observed that dMO ACs dissociated spontaneously into single cells, indicating a problem with cell adhesion. RNA profiles of these replicates clustered heterogenously in principal component analysis (data not shown), which made it difficult to assess the differentially expressed genes. Since we had found before that the onset of epidermal differentiation in ACs is reflected by major transcriptional changes at neurula stage (NF16;(Angerilli et al., 2018)), we based further analysis on this timepoint. Importantly, MCCs have already been specified in the inner cell layer, and have started to amplify centrioles and to intercalate into the outer cell layer of the epidermis (Deblandre et al, 1999).

We found that the expression of 3686 genes (19.7\% of all genes) were altered in this dataset, the majority of them (2246) being downregulated (Figure 2A and data not shown). We then performed gene ontology enrichment analysis for both transcriptional responses to the altered H4K20 methyl landscape. The group of genes that was upregulated in the Su4-20h dMO condition was enriched for biological processes involved in chromatin organization and remodeling, methylation, gene expression and various metabolic processes (Fig. 2B). In confirmation of previous results (Nicetto et al., 2013), we found oct25/pou5f3.2 and oct91/pou5f3.1 among these genes. In contrast, for the cohort of genes downregulated in $\mathrm{dMO} A C s$, the top twenty entries were all associated with terms 
connected to cilium, centrosome, microtubules and cytoskeleton (Fig. 2C). The most enriched categories relate to "cytoskeleton" and "cilium" and comprise of hundreds of genes, which are typically expressed at medium to high levels in control ACs, and many of them are downregulated in suv4-20h1/h2 depleted chromatin (Figure 2D and E).

Most interestingly, key transcriptional regulators of ciliogenesis were expressed either at normal (foxj1, rfx2) or slightly upregulated levels (mci) in the dMO condition (data not shown), confirming that SUV4-20H1/H2 enzymes are epistatic to these TFs. The widespread downregulation of genes associated with cytoskeleton structures and cilia provides a robust explanation for the specific MCC phenotype arising from suv4-20h1/h2 depletion. This concerted downregulation is inconsistent with the removal of repressive H4K20m3 from chromatin. Thus, another mechanism acting in a genome wide manner seems to be responsible.

\section{A genome-wide switch towards H4K20me1 specifically affects cytoskeleton gene expression in differentiating epidermis}

The chromatin of SUV4-20H1/H2 depleted embryos is highly enriched for H4K20m1. This modification is important for mouse development (Oda et al., 2009) and frequently found on promoters and coding regions of genes (Barski et al, 2007). Importantly, whether it represses or activates gene transcription has remained under dispute (for a discussion see (Beck et al., 2012a). However, several studies on PHF8/KDM7B, a JmjC-domain containing histone demethylase with H4K20me1-specificity, have consistently revealed that increased H4K20me1 levels result in reduced gene expression (Asensio-Juan et al, 2017; Liu et al, 2010; Qi et al, 2010). Of particular interest to us was the finding that PHF8 knockdown in mammalian cells and primary mouse neurons caused an increase in H4K20m1 levels at coding regions, a transcriptional repression of cytoskeletal genes, impaired cell adhesion, and deficient neurite outgrowth (Asensio-Juan et al, 2012). Based on these phenotypic similarities to SUV4-20H1/H2 dMO Xenopus epidermis, we wondered, whether the increased 
H4K20me1 levels are responsible for the observed ciliogenic phenotype. To address this hypothesis, we overexpressed Phf8 in the dMO context.

We used two Phf8 cDNA clones available from commercial gene repositories: a full-length human clone (hPhf8) and a partial Xenopus phf8 clone (xPHF8 $\Delta \mathrm{C})$. The latter consists of the first 264 aa residues of the xphf8 ORF, including the PHD domain known to target the protein to H3K4m3 marks at active promoters, as well as the first 66 amino acids from the 156-residue long JmjC-domain (Figure S3B). Of the critical amino acid triad His-Asp-His in the catalytic center, the truncated Xenopus protein lacks the third residue involved in Fe-coordination and, thus, is potentially compromised in its catalytic activity (Chaturvedi et al, 2019).

First, we injected hPHF8 mRNA, either alone or in combination with Mos, and evaluated its effect on ciliogenesis by staining half-injected embryos for acetylated-a-tubulin at tailbud stage (Figure 3A). Injection of hPHF8 alone had little to no effect on the density or size of cilia tufts, however, it restored cilia staining significantly in SUV4-20H dMOs. The injected and non-injected sides of PHF8 rescued embryos were indistinguishable in more than $40 \%$ of the inspected cases, while $90 \%$ of dMO embryos had regions devoid of cilia staining. In contrast, co-injection of the same amount of lacZ mRNA had no effect on the phenotype (Figure $3 A$ and $B$ ). In comparable settings, xPHF8 $\Delta C$ mRNA caused with high penetrance (96\%) an increase in MCC numbers and ciliary staining intensity, when injected alone (Figure S3A and C). In addition, it restored ciliogenesis in a significant manner, reducing the frequency of embryos with strongly reduced cilia from $90 \%$ to $25 \%$. In nearly half of the rescued embryos, injected and uninjected sides were indistinguishable (Figure S3A and D). In addition, we confirmed by confocal microscopy in mosaic embryos that both phf8 mRNAs were able to partially restore the assembly of axonemes and improve the density of the apical Actin meshwork, although not to the level of neighbouring wildtype MCCs (Figures 3D and S3E and F). 
These findings stimulated us to investigate the PHF8 dependent changes in gene expression, which accompany this partial morphological rescue. We injected embryos with hPhf8 mRNA alone or in concert with the suv4-20h1/h2 Mos ("hPHF8-rescue" condition). We also injected CoMo, and LacZ mRNA as nonspecific controls. We then dissected ACs from these embryos, harvested them at neurula stage (NF16) and performed RNA-seq analysis with 3 biological replicates for each condition. The results from hPhf8, CoMo and LacZ injected explants were highly similar (data not shown). In order to stringently isolate the rescuing effect of Phf8 on the suv4-20h dMO condition, we normalized the transcriptome of hPHF8-rescue ACs by the transcriptome of Phf8-overexpressing ACs (Figure 4). Of genes that were downregulated in the initial suv4-20h1/2 condition about 80 percent had improved their expression. To correlate these changes in gene expression with the observed morphological rescue, we specifically investigated, whether transcript levels of cilium and cytoskeleton genes, which were down in the initial suv4-20h1/2 KD dataset, had improved (Figure 4B and D). Indeed, out of 183 cilium genes, 140 improved their log2-fold change (77\%), while 43 were further downregulated; and out of 367 cytoskeleton genes, 294 were downregulated to a lesser extent (80\%), while 73 were further downregulated (Figure 4A and $\mathrm{C}$ ).

The differential gene expression analysis for the xPHF8 $\Delta$ C-rescue suggested that this truncated enzyme had a stronger activity on its own than the full-length human protein (Figure S4). By comparison of the log2-fold changes, xPHF8 $\Delta \mathrm{C}$ clearly improved the expression levels of cilium and cytoskeleton genes, which were down in suv4-20h dMO condition (Figure S4D and F). This was found for 176/183 (96\%) cilia genes and 344/363 (95\%) cytoskeleton genes (Figure S4E and $\mathrm{G})$.

All together, these results indicate that overexpression of the histone demethylase PHF8 has an influence on gene transcription in H4K20m1-enriched chromatin of suv4-20h depleted epidermal organoids. Improving the expression levels for a large majority of cilium and cytoskeleton genes that were down in 
SUV4-20H1/H2 depleted epidermis is compatible with the observed partial rescue of cilia tufts on the morphological level, and supports the hypothesis that the ciliogenic defect is caused through gene repression by H4K20m1.

\section{SUV4-20H1 is required for multiciliated cell differentiation}

The suv4-20h1 gene is essential for mouse development and responsible for writing the H4K20m2 mark, while suv4-20h2 appears to be responsible for H4K20 trimethylation. Double null MEFs have lost H4K20 di- and trimethylation almost completely, without concomitant changes in acetylation or methylation levels at histone H3 lysines 9, 14, 23, 27 and 36 in bulk chromatin (Schotta et al, 2008). Knocking down both SUV4-20H homologs in Xenopus leads to a similar shift in H4K20 methylation states towards H4K20m1 (Figure 1A). This leads to transcriptional upregulation of some genes, which are repressed by H4K20m3, such as the mammalian OCT4-related genes oct25/pou5f3.2 and oct91/pou5f3.1 (Nicetto et al., 2013). Our results from PHF8-rescue experiments in double morphant explants strongly suggest that the loss of SUV4-20H1 activity alone could already induce the ciliogenic defect during epidermal differentiation in Xenopus.

To verify this assumption, we unilaterally injected embryos with either suv4-20h1 Mo, suv4-20h2 Mo, or both and determined the effects by immunostaining for cilia tufts. As shown in Supplementary Figure 5A, the KD of SUV4-20H1 alone elicited the loss of cilia to a similar extent as the double KD of both enzymes (Figure S5B). Importantly, SUV4-20H2 depleted embryos display wildtype-like cilia tufts. In a separate experimental series, we confirmed that PHF8 partially restored ciliogenesis in SUV4-20H1 morphant explants by immunostaining (Figure 5C and D). Confocal microscopy revealed that this improves both formation of the apical actin cap and assembly of ciliary axonemes (Figure 5E). Therefore, the conversion of H4K20m1 to H4K2Om2 by SUV-20H1 is essential for the differentiation of MCCs, while SUV4-20H2 is not.

\section{DISCUSSION}


The SUV4-20H1 enzyme converts H4K20m1 to the di-methylated state and is largely responsible for making its product the most abundant histone modification in vertebrate chromatin (Jorgensen et al., 2013; Pesavento et al., 2008). The work presented here has elucidated an unexpected and novel function for this enzyme in developing Xenopus embryos. On the morphological level we have initially found that SUV4-20H1/H2 enzymes are needed in postmitotic MCC precursor cells at their time of differentiation to support production of a large number of motile cilia on their apical surface in the larval epidermis. These cilia tufts are needed for the generation of directional flow, a hallmark of all mucociliary epithelia (Boutin \& Kodjabachian, 2019). This morphological phenotype is specific, since it was reproduced with a second pair of suv420h1/h2-specific Morpholino oligonucleotides. Furthermore, it was significantly rescued by injecting morpholino-insensitive suv4-20h1/h2 mRNAs, as well as by overexpression of the histone demethylase PHF8, which antagonizes the consequences of SUV4-20H1/H2 protein knockdown by removing the methyl group from hyper-accumulated H4K20m1. It should be noted that besides PHF8 there are additional enzymes, which demethylate H4K20 (Brejc et al, 2017; Cao et al, 2020). It is currently unknown, whether any of these is involved in MCC differentiation.

Differential gene expression analysis for control and SUV4-20H dMO ACs identified the underlying cause of the phenotype by revealing the concerted downregulation of about 500 genes associated with the GO terms "cilium" and "cytoskeleton". The expression of $75 \%$ of them was improved by overexpression of PHF8 in SUV4-20H dMOs, consistent with the observed morphological rescue under this condition. Their improved expression is most likely due to changing $\mathrm{H} 4 \mathrm{~K} 20 \mathrm{~m} 1$ to unmethylated H4K20, which is neutral in terms of transcription. This is in agreement with a previous study, which knocked down PHF8 in mammalian cells and observed a local increase in H4K20m1 deposition at coding genes, whose expression was downregulated (Asensio-Juan et al., 2017). Up to now we have not established any of the 500 genes as direct targets of H4K20m1 
repression. The results from RNA profiling and cell morphological analysis, however, let us conclude that enhanced levels of H4K20m1 in chromatin is incompatible with an adequate expression of many cilium and cytoskeleton associated genes needed to support cilia tuft formation in multiciliated cells.

We subsequently found that the ciliogenic phenotype depends solely on suv420h1 knock down (Figure 5), and thus involves only H4K20m1 and H4K20m2 marks. This result was instrumental to formulate our model (Figure 6), which connects the ciliogenic phenotype to the cell cycle phase-specific regulation of H4K20 methylation. This model predicts that accumulation of H4K20m1 in G2phase phase would safeguard the genome during mitosis by repressing the expression of cytoskeleton genes that interfere with either centrosome/MTOC function and/or assembly of the mitotic spindle. The incompatibility between G2/M- and G1/G0-specific gene expression programs could arise from the shared use of proteins (e.g., tubulins) and organizing hubs (e.g., centrioles/basal bodies). A major goal for the future lies in identifying the cilium/cytoskeleton genes, which need to be regulated in this manner. Once a cell exits the cell cycle, SUV4-20H1 converts H4K20m1 to H4K20m2, thereby upregulating the genes needed to form stable macromolecular assemblies in line with differentiation, such as cilia tufts, neurite outgrowths or focal adhesions. Based on this model, the ciliogenic phenotype in Xenopus MCCs is interpreted to arise from a G2-like chromatin state in a G0 cellular environment.

The significance of this model is illustrated by several studies. For instance, Julien and Herr demonstrated that depletion of the abundant chromatin protein $\mathrm{HCF}-1_{c}$ causes a switch from H4K20m1 to H4K20m2 on mitotic chromatin, which is associated with defective chromosome alignment and segregation (Julien \& Herr, 2004). Another striking example is provided by the conserved CDK1-APC/C mitotic oscillator, which at high activity levels controls entry and exit of mitosis, while at reduced levels coordinates the progression of organelle remodeling associated with motile ciliogenesis (Al Jord et al, 2019). Thus, postmitotic cells redeploy the mitotic oscillator to coordinate centriole amplification during 
multiciliogenesis (Al Jord et al, 2017). Although it is currently unclear, how the activity of the mitotic oscillator gets calibrated in postmitotic cells to avoid triggering mitosis, it is possible that the concerted upregulation of $\mathrm{H} 4 \mathrm{~K} 20 \mathrm{~m} 1$ repressed genes by SUV4-20H1 could tip the balance in favor of cytoplasmic organelle remodelling.

We assume that the fundamental mechanism we have described here has not been recognized before, since the majority of studies on histone modifications, including H4K20, were performed in proliferating cells, which are largely undifferentiated. We have detected this mechanism in the highly dynamic context of developing frog embryos, in which cells at given times stop to proliferate and switch on differentiation programs, which let them assemble diverse cytoskeletal structures depending on the cell type. It is important to recognize that the histone modification landscape of cells, which undergo this switch, is challenged by the sudden disappearance of S-phase dilution of parental histone marks through incorporation of newly synthesized, unmodified histones (Alabert et al., 2015). This indeed influences epigenetic information, since histone PTMs are propagated across the cell cycle by at least two distinct kinetic modes (ibid.). In collaboration with Carsten Marr's lab, we have recently found by computational modeling that dilution through DNA replication is sufficient to explain the measured abundance of H4K20me states in proliferating embryos, while active demethylation is needed to shape histone methylation levels in G1-arrested embryos (Schuh et al, 2020). We therefore believe that for a deeper understanding of histone PTMs and their impact on cellular morphology, it will be necessary to investigate the chromatin landscape in differentiated, nonproliferating cells, which after all constitute the majority of the human body.

On the organismal level, specialized cytoskeletal structures play a role in the etiology of many human diseases. For example, defects in motile cilia formation are accountable for polycystic kidney disease, Meckel-Gruber syndrome or Leber's congenital amaurosis (Waters \& Beales, 2011). Moreover cilia are essential for the mucociliary clearance in the lung and thus play a pivotal role in 
several diseases where clearance is impaired, such as cystic fibrosis, asthma or chronic bronchitis (Tilley et al, 2015). Our data show that it is possible to manipulate the amount of cilia in both directions by acting on the chromatin enzymes that regulate the abundance of H4K20 methylation. In fact, these enzymes are druggable and small molecule inhibitors for SUV4-20H enzymes and JmjC-domain containing proteins like PHF8 are available (Bromberg et al, 2017; Schiller et al, 2014). We suggest that manipulating H4K20 methylation states could have a therapeutic potential for diseases of unclear etiology that affect tubulin- or actin-based cytoskeleton structures.

\section{ACKNOWLEDGEMENTS}

We thank Daniil Pokrovsky for helpful comments on the manuscript and its original submission; Barbara Hölscher for exceptional embryo stainings; Drs. Hiroshi Kimura, Chris Kintner, Gunnar Schotta, Axel Schweickert, and Peter Walentek for their kind gift of antibodies and recombinant plasmids; Dr. Andreas Thomae and the Core Facility of Bioimaging of the Biomedical Center for instructions and technical support in confocal imaging. This work was funded by the Deutsche Forschungsgemeinschaft (DFG, German Research Foundation) Project-ID 213249687 - SFB 1064 (Project A12).

\section{MATERIALS AND METHODS}

\section{Ethics statement}

Xenopus experiments adhere to the protocol on the protection and Welfare of Animals of the European Commission and are approved by the local Animal Care authorities.

\section{Embryo handling and $\mathrm{AC}$ preparation}

$X$. laevis embryos were handled and fertilized in vitro using standard procedures. $X$. tropicalis embryos were handled and in vitro fertilized as described (Showell \& Conlon, 2009). Embryos were injected with volumes up to 10nl. 2-cell stage 
injected embryos were co-injected with Alexa Fluor-488 Dextran (Invitrogen) as a lineage tracer and sorted by left or right-side injection. Whole embryos were staged according to the Normal Table (Nieuwkoop \& Faber, 1967). X. tropicalis animal caps (ACs) were manually dissected and staged based on sibling embryos.

\section{Expression constructs and morpholino oligonucleotides}

Full length human phf8 cDNA in pCMV-SPORT6 and truncated xphf8 (xphf8 $\Delta \mathrm{C})$ in pCS108 were obtained from Dharmacon ${ }^{\mathrm{TM}} /$ Horizon Discovery (Cambridge UK). The following published plasmid constructs were used: Mci-HGR in pCS2+ was kindly provided by P. Walentek. Foxj1 in PCS2+ was kindly provided by A. Schweikert. Synthetic mRNAs were injected into embryos at the 2- or 8-cell stage.

Translation-blocking Morpholino oligonucleotides (Mo) directed against Xenopus suv4-20h1 (X. laevis, X. tropicalis suv4-20h1 5'-ggattcgcccaaccacttcatgcca-3') and suv4-20h2 (X. laevis suv4-20h2: 5'-ttgccgtcaaccgatttgaacccat-3', X. tropicalis suv4-20h2: 5'-ccgtcaagcgatttgaacccatagt-3') and standard control Mo (5'-cctcttacctcagttacaatttata-3') were obtained from Gene Tools LLC. X. laevis embryos were injected with 30-40ng of each Mo per blastomere into the animal pole of one blastomere at the 2-cell stage. For confocal analysis, X. laevis embryos were injected at the 8-cell stage in one dorsal blastomere with $5 \mathrm{ng}$ of each morpholino in $2.5 \mathrm{nl}$ (control morpholino=10ng). X. tropicalis embryos were injected with $20 \mathrm{ng}$ of each morpholino. Rescue experiments were performed by co-injecting suv4-20h1/2 Mos with 900pg of hphf8 mRNA, 500pg of xphf8 $\Delta \mathrm{C}$ mRNA, and equivalent amounts of lacZ mRNA.

\section{SDS-PAGE and western blot analysis}

For Western Blot analysis the following primary antibodies were used: H4K20me1 1:2500 dilution kindly provided by H. Kimura (Kimura et al, 2015), H4K20me2 1:500 kindly provided by G. Schotta (Schotta et al., 2008), H4K20me3 1:1000 (Abcam Ab9053), panH3 1:10000 (Abcam Ab1791), Anti- 
mouse 1:2500 (Jackson Immunoresearch 115-035-003), Anti-rabbit 1:5000 (Jackson Immunoresearch 1:10000).

\section{Immunocytochemistry}

ICC was performed as described (Robinson \& Guille, 1999). For confocal analysis standard methanol step was avoided. Embryos were stained with: 1:500 monoclonal anti-acetylated tubulin antibody Sigma-Aldrich (T6793), $25 \mu \mathrm{M} \mathrm{DAPI,}$ $0.33 \mu \mathrm{M}$ phalloidin-Alexa 555 Thermo-Fischer Scientific (A34055). Depending on the analysis, embryos were incubated with secondary Goat anti-mouse conjugated to Alexa 647 (Thermo-Fischer Scientific A21236) or alkaline phosphatase-fused secondary Sheep anti-mouse (Chemicon AP303A). antibodies.

\section{Statistical Analysis}

ICC results from knockdown experiments were analysis using a two-tailed Student's t-test. Results from rescue experiments were analysed using one-way ANOVA with post-hoc Tukey test.

\section{RNA library preparation and sequencing}

Total RNA was isolated and purified from approximately $30 \mathrm{X}$. tropicalis ACs using TRIzol (Ambion) and phenol/chloroform extraction, followed by clean-up with RNeasy Mini-Kit (Qiagen). RNA Integrity Number (RIN) was analysed using an Agilent 2100 Bioanalyzer in order to monitor RNA quality (Schroeder et al, 2006). Ribosomal RNA was removed from 500ng of input RNA using either RiboZero Gold rRNA Removal Kit (Human/Mouse/Rat) from Illumina or NEBNext rRNA Depletion Kit (Human/ Mouse/ Rat). Then, total stranded RNA sequencing libraries were prepared using NEBNext Ultra ${ }^{\mathrm{TM}}$ Directional RNA Library Prep Kit for Illumina following the manufacturer's instructions. Quality and size of libraries were verified using the Agilent Bioanalyzer with the Agilent DNA 100 kit. RNA libraries were multiplexed and sequenced with 50 base pair (bp), paired-end reads to a depth of 30 million reads per sample on an Illumina HiSeq4000. 


\section{RNA-seq analysis}

Sequencing reads $(50 \mathrm{bp})$ were mapped to the reference genome (X. tropicalis v9.1 available from Xenbase) using STAR (version 2.7.1a). Gene models were provided as a gtf file, which was converted from the Xenbase gff3 format using Cufflinks gffread (version 2.2.1). Reads were counted for each gene in the same STAR run by the quantMode GeneCounts.

Downstream analyses were carried out in $\mathrm{R}$ (version 3.6.1) using helper function from the HelpersforDESeq2 package (version 0.1; https://github.com/tschauer/HelpersforDESeq2). Differential analysis was performed by DESeq2 (version 1.26) on the three datasets separately. Genes with at least 1 mapped read detected in 75 percent of the samples in the given dataset were considered. Significantly differential genes were defined by an adjusted $p$-value cutoff of 0.05 . Results were visualized as MA plots, where the $x$ axis indicates the $\log 10$ mean counts and the $y$-axis the log2 fold change (log2FC). Comparison of the independent datasets was visualized by log2FClog2FC plots, where the shown condition was compared to its own control.

Gene ontology annotation was derived from the mouse org.Mm.eg.db package (version 3.8.2) by converting gene ids from mouse to Xenopus. Genes annotated with cellular component "cilium" or "cytoskeleton" were selected by the GO ids "GO:0005929" or "GO:0005856" as well as all their offspring terms, respectively. $\mathrm{GO}$ enrichment analysis was performed by the topGO package (version 2.36.0) using Fisher statistics. GO results were visualized as bubble plots, where the $\mathrm{x}$ axis indicates the fold enrichment (i.e. the observed number of significant genes for the GO term over the expected number), the bubble size is proportional to the number of significant genes for the GO term and the color intensity is related to the Fisher test $p$-value. 


\section{REFERENCES}

Al Jord A, Shihavuddin A, Servignat d'Aout R, Faucourt M, Genovesio A, Karaiskou A, Sobczak-Thepot J, Spassky N, Meunier A (2017) Calibrated mitotic oscillator drives motile ciliogenesis. Science 358: 803-806

Al Jord A, Spassky N, Meunier A (2019) Motile ciliogenesis and the mitotic prism. Biol Cell 111: 199-212

Alabert C, Barth TK, Reveron-Gomez N, Sidoli S, Schmidt A, Jensen ON, Imhof A, Groth A (2015) Two distinct modes for propagation of histone PTMs across the cell cycle. Genes Dev 29: 585-590

Angerilli A, Smialowski P, Rupp RA (2018) The Xenopus animal cap transcriptome: building a mucociliary epithelium. Nucleic Acids Res 46: 87728787

Asensio-Juan E, Fueyo R, Pappa S, lacobucci S, Badosa C, Lois S, Balada M, Bosch-Presegue L, Vaquero A, Gutierrez S et al (2017) The histone demethylase PHF8 is a molecular safeguard of the IFNgamma response. Nucleic Acids Res 45: 3800-3811

Asensio-Juan E, Gallego C, Martinez-Balbas MA (2012) The histone demethylase PHF8 is essential for cytoskeleton dynamics. Nucleic Acids Res 40: 9429-9440

Barski A, Cuddapah S, Cui K, Roh TY, Schones DE, Wang Z, Wei G, Chepelev I, Zhao K (2007) High-resolution profiling of histone methylations in the human genome. Cell 129: 823-837

Beck DB, Burton A, Oda H, Ziegler-Birling C, Torres-Padilla ME, Reinberg D (2012a) The role of PR-Set7 in replication licensing depends on Suv4-20h. Genes Dev 26: 2580-2589

Beck DB, Oda H, Shen SS, Reinberg D (2012b) PR-Set7 and H4K20me1: at the crossroads of genome integrity, cell cycle, chromosome condensation, and transcription. Genes Dev 26: 325-337

Boutin C, Kodjabachian L (2019) Biology of multiciliated cells. Curr Opin Genet Dev 56: 1-7 
Brejc K, Bian Q, Uzawa S, Wheeler BS, Anderson EC, King DS, Kranzusch PJ, Preston CG, Meyer BJ (2017) Dynamic Control of X Chromosome Conformation and Repression by a Histone H4K20 Demethylase. Cell 171: 85-102 e123

Bromberg KD, Mitchell TR, Upadhyay AK, Jakob CG, Jhala MA, Comess KM, Lasko LM, Li C, Tuzon CT, Dai Y et al (2017) The SUV4-20 inhibitor A-196 verifies a role for epigenetics in genomic integrity. Nat Chem Biol 13: 317-324

Brooks ER, Wallingford JB (2014) Multiciliated cells. Curr Biol 24: R973-982 Cao X, Chen Y, Wu B, Wang X, Xue H, Yu L, Li J, Wang Y, Wang W, Xu Q et al (2020) Histone H4K20 Demethylation by Two hHR23 Proteins. Cell Rep 30: 4152-4164 e4156

Chaturvedi SS, Ramanan R, Waheed SO, Karabencheva-Christova TG, Christov CZ (2019) Structure-function relationships in KDM7 histone demethylases. Adv Protein Chem Struct Biol 117: 113-125

Dammermann A, Pemble H, Mitchell BJ, McLeod I, Yates JR, 3rd, Kintner C, Desai AB, Oegema K (2009) The hydrolethalus syndrome protein HYLS-1 links core centriole structure to cilia formation. Genes Dev 23: 2046-2059

Deblandre GA, Wettstein DA, Koyano-Nakagawa N, Kintner C (1999) A two-step mechanism generates the spacing pattern of the ciliated cells in the skin of Xenopus embryos. Development 126: 4715-4728

Hahn M, Dambacher S, Dulev S, Kuznetsova AY, Eck S, Worz S, Sadic D, Schulte M, Mallm JP, Maiser A et al (2013) Suv4-20h2 mediates chromatin compaction and is important for cohesin recruitment to heterochromatin. Genes Dev 27: 859-872

Hyun K, Jeon J, Park K, Kim J (2017) Writing, erasing and reading histone lysine methylations. Exp Mol Med 49: e324

Jorgensen S, Schotta G, Sorensen CS (2013) Histone H4 lysine 20 methylation: key player in epigenetic regulation of genomic integrity. Nucleic Acids Res 41: 2797-2806

Julien E, Herr W (2004) A switch in mitotic histone H4 lysine 20 methylation status is linked to M phase defects upon loss of HCF-1. Mol Cell 14: 713-725 
Kimura H, Hayashi-Takanaka Y, Stasevich TJ, Sato $Y$ (2015) Visualizing posttranslational and epigenetic modifications of endogenous proteins in vivo. Histochem Cell Biol 144: 101-109

Liu W, Tanasa B, Tyurina OV, Zhou TY, Gassmann R, Liu WT, Ohgi KA, Benner C, Garcia-Bassets I, Aggarwal AK et al (2010) PHF8 mediates histone H4 lysine 20 demethylation events involved in cell cycle progression. Nature 466: 508-512 Meunier A, Azimzadeh J (2016) Multiciliated Cells in Animals. Cold Spring Harb Perspect Biol 8

Mitchell B, Stubbs JL, Huisman F, Taborek P, Yu C, Kintner C (2009) The PCP pathway instructs the planar orientation of ciliated cells in the Xenopus larval skin. Curr Biol 19: 924-929

Nicetto D, Hahn M, Jung J, Schneider TD, Straub T, David R, Schotta G, Rupp RA (2013) Suv4-20h histone methyltransferases promote neuroectodermal differentiation by silencing the pluripotency-associated Oct-25 gene. PLoS Genet 9: e1003188

Nieuwkoop PD, Faber J (1967) Normal table of Xenopus laevis (Daudin): A systematical and chronological survey of the development from the fertilized egg till the end of metamorphosis. North-Holland, Amsterdam

Oda H, Okamoto I, Murphy N, Chu J, Price SM, Shen MM, Torres-Padilla ME, Heard E, Reinberg D (2009) Monomethylation of histone H4-lysine 20 is involved in chromosome structure and stability and is essential for mouse development. Mol Cell Biol 29: 2278-2295

Pannetier M, Julien E, Schotta G, Tardat M, Sardet C, Jenuwein T, Feil R (2008) PR-SET7 and SUV4-20H regulate H4 lysine-20 methylation at imprinting control regions in the mouse. EMBO Rep 9: 998-1005

Pesavento JJ, Yang H, Kelleher NL, Mizzen CA (2008) Certain and progressive methylation of histone $\mathrm{H} 4$ at lysine 20 during the cell cycle. Mol Cell Biol 28: 468486

Petryk N, Dalby M, Wenger A, Stromme CB, Strandsby A, Andersson R, Groth A (2018) MCM2 promotes symmetric inheritance of modified histones during DNA replication. Science 361: 1389-1392 
Pokrovsky D, Forné I, Straub T, Imhof A, Rupp RAW (2020) Mitotic activity shapes stage-specific histone modification profiles during Xenopus embrogenesis. BioRxiv 2020.08.04.200550

Popov IK, Kwon T, Crossman DK, Crowley MR, Wallingford JB, Chang C (2017) Identification of new regulators of embryonic patterning and morphogenesis in Xenopus gastrulae by RNA sequencing. Dev Biol 426: 429-441

Qi HH, Sarkissian M, Hu GQ, Wang Z, Bhattacharjee A, Gordon DB, Gonzales M, Lan F, Ongusaha PP, Huarte $M$ et al (2010) Histone H4K20/H3K9 demethylase PHF8 regulates zebrafish brain and craniofacial development. Nature 466: 503-507

Quigley IK, Kintner C (2017) Rfx2 Stabilizes Foxj1 Binding at Chromatin Loops to Enable Multiciliated Cell Gene Expression. PLoS Genet 13: e1006538

Robinson C, Guille M (1999) Immunohistochemistry of Xenopus embryos. Methods Mol Biol 127: 89-97

Saksouk N, Barth TK, Ziegler-Birling C, Olova N, Nowak A, Rey E, MateosLangerak J, Urbach S, Reik W, Torres-Padilla ME et al (2014) Redundant mechanisms to form silent chromatin at pericentromeric regions rely on BEND3 and DNA methylation. Mol Cell 56: 580-594

Scharf AN, Barth TK, Imhof A (2009) Establishment of histone modifications after chromatin assembly. Nucleic Acids Res 37: 5032-5040

Schiller R, Scozzafava G, Tumber A, Wickens JR, Bush JT, Rai G, Lejeune C, Choi H, Yeh TL, Chan MC et al (2014) A cell-permeable ester derivative of the JmjC histone demethylase inhibitor IOX1. ChemMedChem 9: 566-571

Schotta G, Lachner M, Sarma K, Ebert A, Sengupta R, Reuter G, Reinberg D, Jenuwein $T$ (2004) A silencing pathway to induce H3-K9 and H4-K20 trimethylation at constitutive heterochromatin. Genes Dev 18: 1251-1262

Schotta G, Sengupta R, Kubicek S, Malin S, Kauer M, Callen E, Celeste A, Pagani M, Opravil S, De La Rosa-Velazquez IA et al (2008) A chromatin-wide transition to H4K20 monomethylation impairs genome integrity and programmed DNA rearrangements in the mouse. Genes Dev 22: 2048-2061 
Schroeder A, Mueller O, Stocker S, Salowsky R, Leiber M, Gassmann M, Lightfoot S, Menzel W, Granzow M, Ragg T (2006) The RIN: an RNA integrity number for assigning integrity values to RNA measurements. BMC Mol Biol 7: 3

Schuh L, Loos C, Pokrovsky D, Imhof A, Rupp RAW, Marr C (2020) H4K20 methylation kinetics are differently regulated by dilution and demethylation in proliferating and cell-cycle arrested Xenopus embryos. Cell Systems in press Sedzinski J, Hannezo E, Tu F, Biro M, Wallingford JB (2016) Emergence of an Apical Epithelial Cell Surface In Vivo. Dev Cell 36: 24-35

Shoaib M, Walter D, Gillespie PJ, Izard F, Fahrenkrog B, Lleres D, Lerdrup M, Johansen JV, Hansen K, Julien E et al (2018) Histone H4K20 methylation mediated chromatin compaction threshold ensures genome integrity by limiting DNA replication licensing. Nat Commun 9: 3704

Showell C, Conlon FL (2009) Egg collection and in vitro fertilization of the western clawed frog Xenopus tropicalis. Cold Spring Harb Protoc 2009: pdb prot5293

Tilley AE, Walters MS, Shaykhiev R, Crystal RG (2015) Cilia dysfunction in lung disease. Annu Rev Physiol 77: 379-406

Walentek P, Beyer T, Hagenlocher C, Muller C, Feistel K, Schweickert A, Harland RM, Blum M (2015) ATP4a is required for development and function of the Xenopus mucociliary epidermis - a potential model to study proton pump inhibitor-associated pneumonia. Dev Biol 408: 292-304

Waters AM, Beales PL (2011) Ciliopathies: an expanding disease spectrum. Pediatr Nephrol 26: 1039-1056

\section{Figure legends}

Figure 1: SUV4-20H1/H2 enzymes are required for ciliogenesis. A) Western Blot analysis of H4K20 methylation states upon KD of the SUV4-20H1/H2 enzymes, individually ( $\mathrm{H} 1 \mathrm{Mo}, \mathrm{H} 2 \mathrm{Mo})$ or in concert $(\mathrm{H} 1 \mathrm{H} 2 \mathrm{Mo})(\mathrm{n}=2$ biological replicates). B) Immunocytochemistry against acetylated-alpha tubulin on embryos that were half injected with either the control or both $\mathrm{H} 1 / \mathrm{H} 2$ Mo $(\mathrm{n}=6$ biol. repl.). C) Penetrance of the phenotype presented in panel B. Panels D-G: Confocal analysis of multiciliated cells on the embryonic epidermis in embryos that were mosaically injected with either control morpholino (CoMo) or the $\mathrm{H} 1 \mathrm{H} 2$ 
Mo. In green are shown the basal bodies, in red the actin meshwork, in magenta the ciliary axonemes and in blue the cell nuclei. Images: 1 shows a representative MCC, 2 shows overlap between the actin cap staining and the basal bodies on the apical surface, 3 shows only the basal bodies on the uppermost Z-sections, 4 shows an apical view of the basal bodies, 5 shows a deep Z-section close to the cell nucleus. E) Confocal analysis of the actin meshwork and docked basal bodies in CoMo or H1H2Mo injected MCC. Panels F \& G: Quantification of the number of MCCs showing reduced cilia (as observed in panel D) and filamentous actin staining (as in panel E) following confocal analysis. We measured $144 \mathrm{CoMo}$ and $163 \mathrm{H} 1 \mathrm{H} 2 \mathrm{Mo}$ injected multiciliated cells. Error bars represent standard deviations. For cilia $\mathrm{p}<3.61522 \mathrm{E}-08$ while for actin $\mathrm{p}<3.50952 \mathrm{E}-11$.

Figure 2: The transcriptome of SUV4-20H1/H2 depleted ACs reveals a link to cilogenesis. A) Number of misregulated genes in suv4-20h1/2 deficient NF16 ACs (significantly misregulated genes with adjusted $p$-value (padj) < 0.05 ). B) Gene ontology (GO) enrichment (biological process) for upregulated genes in suv4-20h1/2 morpholino injected ACs compared to control morpholino injected ACs. Bubble size represents number of significant genes per GO term and bubble colour represents p-value). C) GO enrichment for downregulated genes (cellular component) in suv4-20h1/2 morpholino injected ACs compared to control morpholino injected ACs. Bubble size represents number of significant genes per GO term and bubble colour represents $p$ value). D, E) Gene expression in suv4-20h1/2 morpholino injected ACs compared to control morpholino injected ACs. Each dot represents a single gene. Non-significant genes are indicated in light grey and significant in orange (padj < 0.05). Cytoskeletal genes and cilium genes (as defined by R/Bioconductor package: org.Mm.eg.db version 3.8.2, mouse annotation) are indicated in black (nonsignificant, padj $>$.05), and red (significant, padj < 0.05).

Figure 3: Rescue of the ciliogenic phenotype with hPHF8. A) Immunocytochemistry against acetylated alpha-tubulin of embryos that were injected with either: CoMo, H1H2Mo, H1H2Mo + 900pg of hPhf8 mRNA or $\mathrm{H} 1 \mathrm{H} 2 \mathrm{Mo}+900 \mathrm{pg}$ of LacZ mRNA. Scale bar is $1 \mathrm{~mm}$. B) Quantification of cilia staining from $A$ ) in the 4 given conditions ( $n=3$ biol. Replicates; CoMo vs. H1H2Mo: padj = 1.4E-06; H1H2Mo vs. H1H2Mo+LacZ: padj = 0.82; H1H2Mo vs. $\mathrm{H} 1 \mathrm{H} 2 \mathrm{Mo}+\mathrm{PHF} 8$ : padj = 1.132E-4; H1H2Mo+LacZ vs. H1H2Mo+PHF8: padj = $1.875 \mathrm{E}-4)$. D) Confocal analysis of the rescue with hPhf8 in embryos injected mosaically in 1 blastomere at the 8-cell stage. In green are shown the basal 
bodies, in red the actin meshwork, in magenta the ciliary axonemes and in blue are cell nuclei. ${ }^{*}=$ injected MCCs, wt = wildtype MCCs.

Figure 4: Transcriptomic analysis of hPHF8-rescued ACs. Neurula stage (NF16). (B, D) Comparison of log2 fold change between H1H2Mo vs. CoMo injected animal caps to log2 fold change of hPHF8 rescue vs. hPHF8 injected animal caps. Dashed line indicates no difference in expression between the normalized conditions. Cilia genes (B) and cytoskeletal genes (D) that were downregulated in the initial suv4-20h1/2 dMO dataset are indicated in purple. (A, C) Change in expression of cilia and cytoskeletal genes that were downregulated by suv4-20h1/2 knockdown upon hPHF8 rescue.

Figure 5: KD of SUV4-20H1 alone is sufficient to generate ciliogenic phenotype. A) Immunocytochemistry against acetylated alpha tubulin on $X$. tropicalis embryos that were half-injected with the suv4-20h morpholinos individually or in concert. B) Quantification of the experiment in A. For H1Mo $\mathrm{p}<0,0042$, for H2Mo $\mathrm{p}<0,0015$. C) Immunocytochemistry against acetylatedalpha tubulin on embryos that were half injected with CoMo, H1Mo alone, H1Mo + 900pg LacZ mRNA, or H1Mo + 900pg hPHF8 mRNA. N=4 D) Penetrance of the phenotype presented in panel $\mathrm{C}$. E) Confocal analysis of multiciliated cells on the embryonic epidermis in embryos that were mosaically injected with $\mathrm{H} 1 \mathrm{Mo}$ alone, H1Mo morpholino + 900pg LacZ mRNA, or H1Mo + 900pg hPHF8 mRNA. The basal bodies are shown in green, the actin meshwork in red, and ciliary axonemes in magenta.

Figure 6: Synchronization of cytoskeletal dynamics with the cell cycle. A) During G2 and M phases of the cell-cycle, most newly synthesized $\mathrm{H} 4$ histones incorporated into chromatin during the preceding S-phase, become monomethylated by PR-Set7/SET8. This modification has a repressive effect on transcription, especially for cilium and cytoskeleton associated genes. B) During the following $\mathrm{G} 1$ and $\mathrm{G} 0$ phases, this repression is released by two alternative mechanisms: i) SUV4-20H1 converts H4K20me1 into H4K20me2 in a genome wide, although not quantitative fashion; ii) H4K20m1-specific demethylases such as PHF8 release repression by removing the methyl group from H4K20m1, probably in a more targeted manner.

\section{Supplementary Figures:}

Figure S1: Morpholino Specificity A) Immunocytochemistry against acetylated alpha tubulin in half injected Xenopus laevis embryos. Embryos were injected with either CoMo, the H1H2Mo, with 300pg of LacZ mRNA, or 300pg of suv4- 
20h1/h2 morpholino-insensitive mRNA ( $\mathrm{H} 1 \mathrm{H} 2$ mRNA) or with $\mathrm{H} 1 \mathrm{H} 2 \mathrm{Mo}$ in combination with the $\mathrm{H}_{1} \mathrm{H} 2$ mRNAs. B) Quantification of the results of the experiments in $\mathrm{A} . \mathrm{N}=3$. C) Immunocytochemistry against acetylated alpha-tubulin in embryos that were half injected with either CoMo, $\mathrm{H} 1 \mathrm{H} 2 \mathrm{Mo}$ or a second non overlapping pair of morpholinos targeting suv4-20h1/h2 (H1H2Mo2). D) shows the quantification of the experiment in C. E) Schematic representation of target regions for primary and upstream morpholinos directed against suv4-20h1 and suv4-20h2.

Figure S2: The cilia phenotype of SUV4-20H1/H2 KD embryos is not rescued by Mci/IDAS or Foxj1. A) Embryos were injected mosaically with control or suv4-20h1/2 morpholinos together with Mci-Gr mRNA. Basal bodies are shown in green, actin meshwork is shown in red, ciliary axonemes are shown in magenta, and DNA is shown in blue. * = injected MCC, wt = wildtype MCC, arrows indicate ectopic cilia. B, C) Quantification of the rescue of B) cilia ( $p=$ 3.07225E-11) and C) actin cap ( $p=3.50369 E-08) .8$ fields of view from 8 CoMo injected embryos and 7 fields of view from $7 \mathrm{H} 1 \mathrm{H} 2 \mathrm{Mo}$ injected embryos were scored. D) Embryos were injected mosaically with CoMo or $\mathrm{H} 1 \mathrm{H} 2 \mathrm{Mo}$ together with foxj1 mRNA. Basal bodies are shown in green, actin meshwork is shown in red, ciliary axonemes are shown in magenta, and DNA is shown in blue. $E, F$ ) Quantification of the rescue of $E)$ cilia $(p=1.1308 E-05)$ and $F)$ actin cap $(p=$ 0.00158683). 5 fields of view from 5 embryos were scored.

Figure S3: Rescue of the ciliogenic phenotype with xPHF8 $\Delta$ C. A) Immunocytochemistry against acetylated alpha-tubulin of embryos that were injected with either: CoMo, $\mathrm{H}_{1 H 2 \mathrm{H}}$, xPHF8 $\Delta \mathrm{C}$ synthetic mRNA or the suv4-20h morpholinos $+300 p g$ of $x P H F 8 \Delta C$ mRNA. Scale bar $=1 \mathrm{~mm}, \mathrm{n}=3$. B) Schematic representation of the structure of PHF8 clones: Full length human PHF8 (hPHF8), wt Xenopus PHF8, and truncated Xenopus PHF8 (xPHF8 $\Delta$ C). C) Quantification of cilia staining in panel $A$ in the four given conditions. $\mathrm{H} 1 \mathrm{H} 2 \mathrm{Mo}$ vs. CoMo padj = 1.3E-06, H1H2Mo vs. $\mathrm{H} 1 \mathrm{H} 2 \mathrm{Mo}+\mathrm{xPHF} 8 \Delta \mathrm{C}$ padj = 3.0E-06, CoMo vs. $\mathrm{H} 1 \mathrm{H} 2 \mathrm{Mo}+\mathrm{xPHF} 8 \Delta \mathrm{C}$ padj $=0.0318$. D) Confocal analysis of the rescue with $x P H F 8 \Delta C$ in embryos injected mosaically in 1 blastomere at the 8-cell stage. In green are shown the basal bodies, in red the actin meshwork, in magenta the ciliary axonemes and in blue are cell nuclei. * = injected MCC, wt = wildtype MCC.

Figure S4: Transcriptomic analysis of $\mathrm{xPHF8} \Delta \mathrm{C}$ rescue ACs. Neurula stage (NF16). B, D) Comparison of log2 fold change between $\mathrm{H} 1 \mathrm{H} 2 \mathrm{Mo}$ vs. CoMo injected animal caps to log2 fold change of $x$ Rescue $\Delta C$ vs. $x P H F 8 \Delta C$ animal 
caps. Cilium genes (B) and cytoskeletal genes (D) that were downregulated in the initial $\mathrm{H} 1 \mathrm{H} 2 \mathrm{Mo}$ dataset are indicated in purple. $\mathrm{A}, \mathrm{C})$ Change in expression of cilia (A) and cytoskeletal genes (C) that were downregulated by SUV4-20H1/2KD with $x P H F 8 \Delta C$ rescue. (A) 176 cilia genes improved their expression, while 7 were further downregulated. (C) 344 cytoskeleton genes improved their expression, while 19 were further downregulated. 


\section{Main Figures}

Figure 1
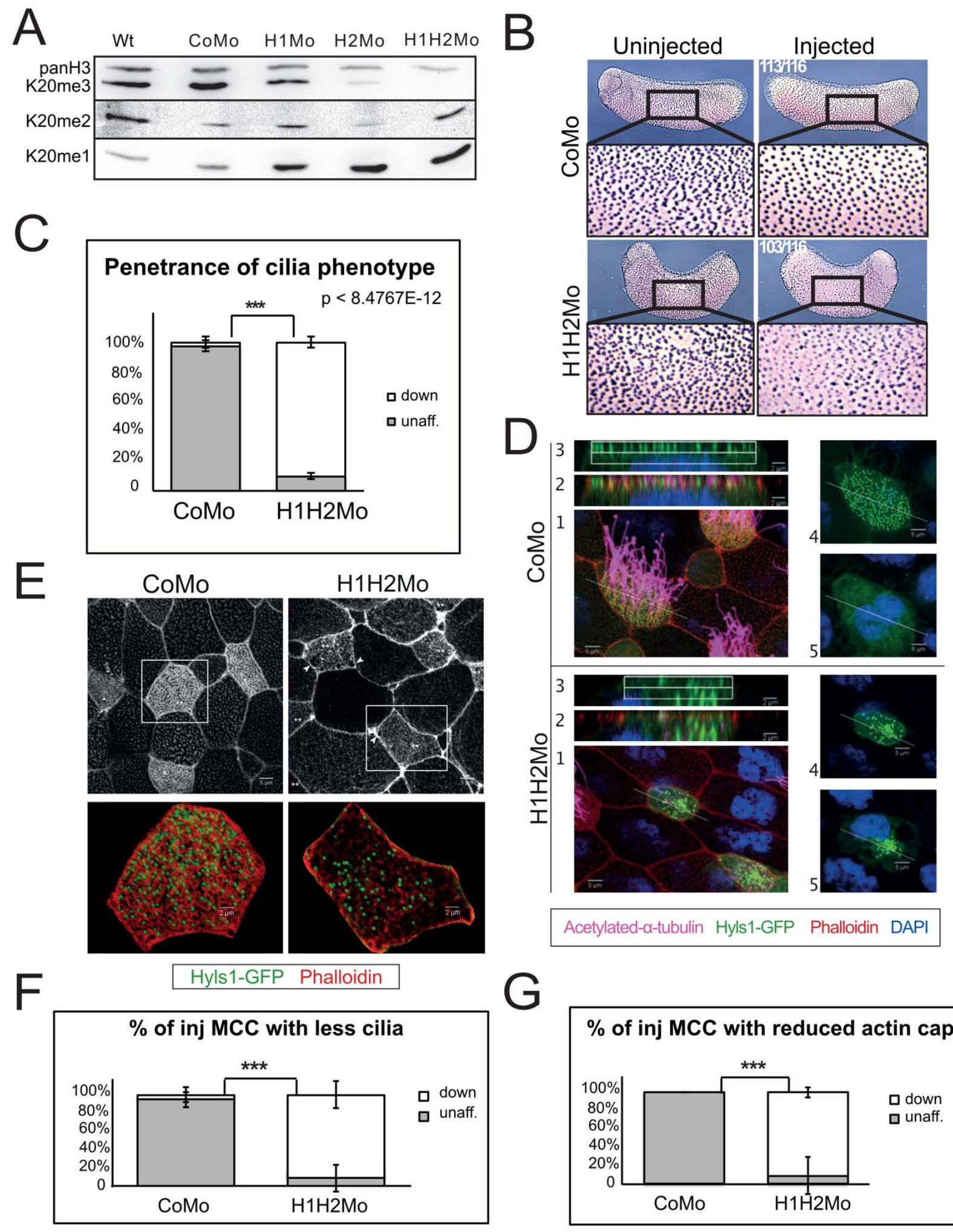

G

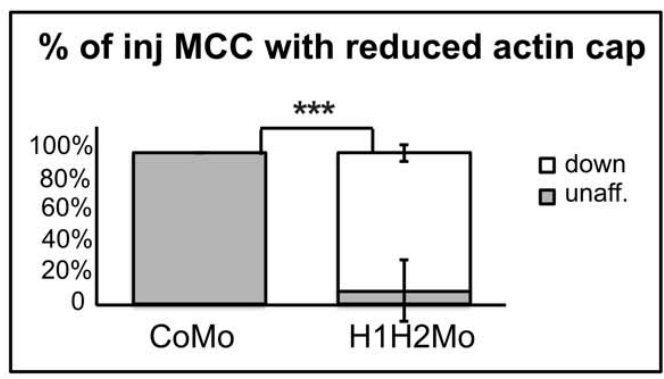


bioRxiv preprint doi: https://doi.org/10.1101/2020.12 01.404053; this version posted December 2, 2020. The copyright holder for this preprint (which was not certified by peer review) is the author/funder, who has granted bioRxiv a license to display the preprint in perpetuity. It is made available under aCC-BY 4.0 International license.

Figure 2

A
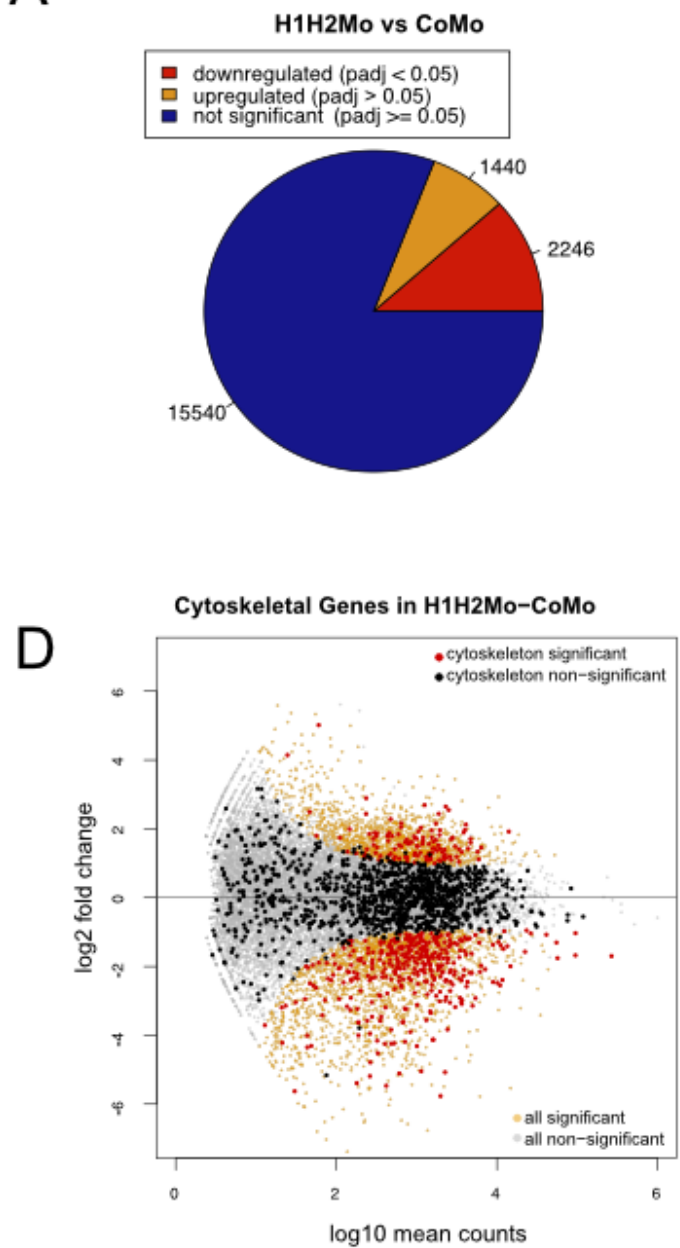

$E$

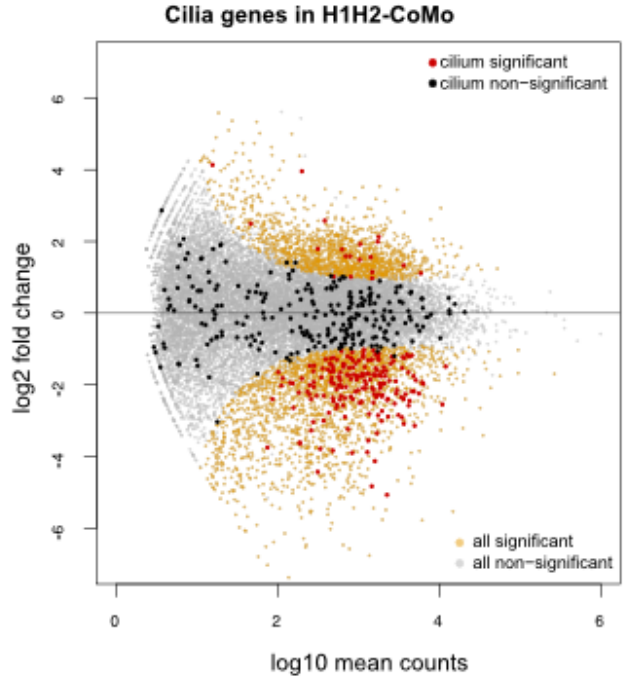

B

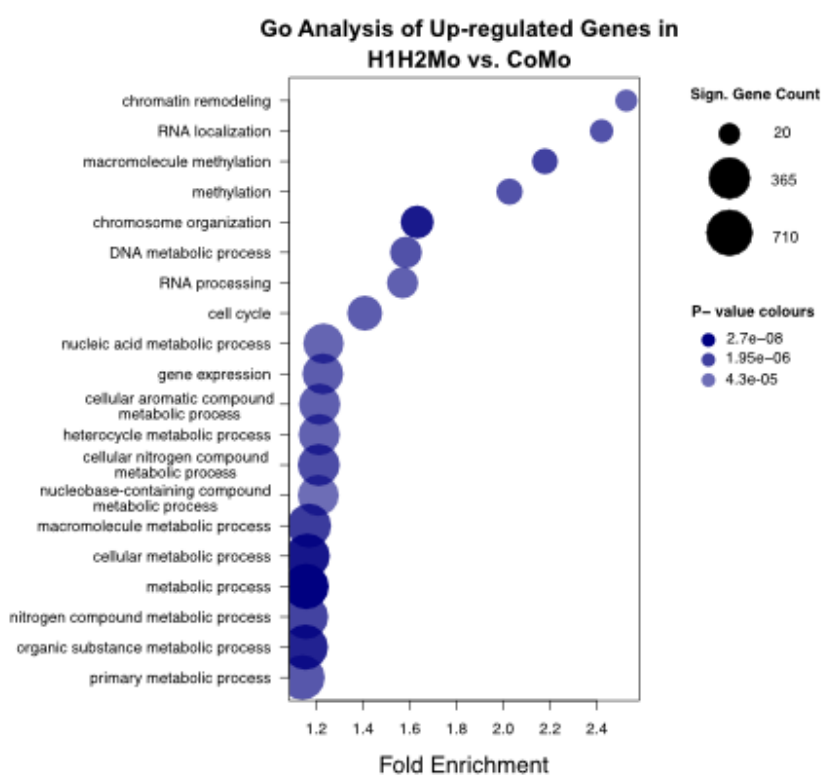

C

Go Analysis of Down-regulated Genes in $\mathrm{H} 1 \mathrm{H} 2 \mathrm{Mo}$ vs. CoMo

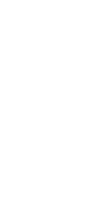

motile cilium
$9+2$ motile cilium
axoneme
cillary plasm
sperm flagellum

ciliary basal body ciliary transition zone plasma membrane bounded
cell projection

cliary part

microtubule organizing centor part

microtubule organizing center

centrosome

cytoskoletal part microtubule cytoskaleton
plasma membrane bounded

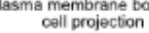

cell projection part

cytoskeleton plasma membrane bounded cell projection
celon

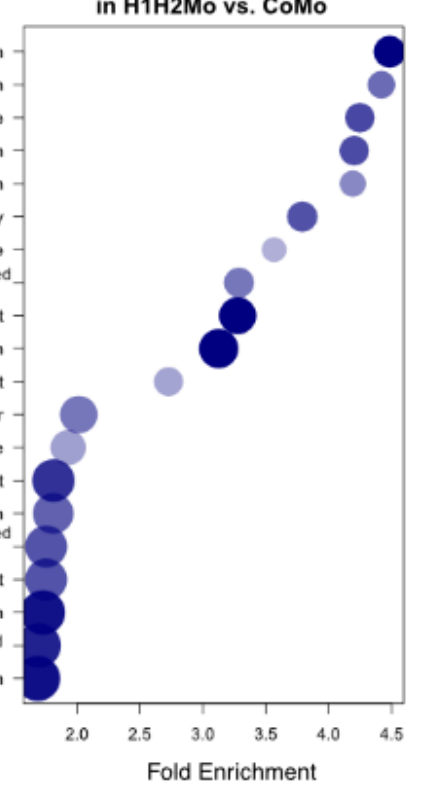

Sign, Gene Count

- 30

( 125

C 400

P - value Colors

- 1e-30

- $5.11825 \mathrm{e}-27$

$3.4 \mathrm{e}-10$ 
bioRxiv preprint doi: https://doi.org/10.1101/2020.12.01.404053; this version posted December 2, 2020. The copyright holder for this preprint (which was not certified by peer review) is the author/funder, who has granted bioRxiv a license to display the preprint in perpetuity. It is made available under aCC-BY 4.0 International license.

Figure 3

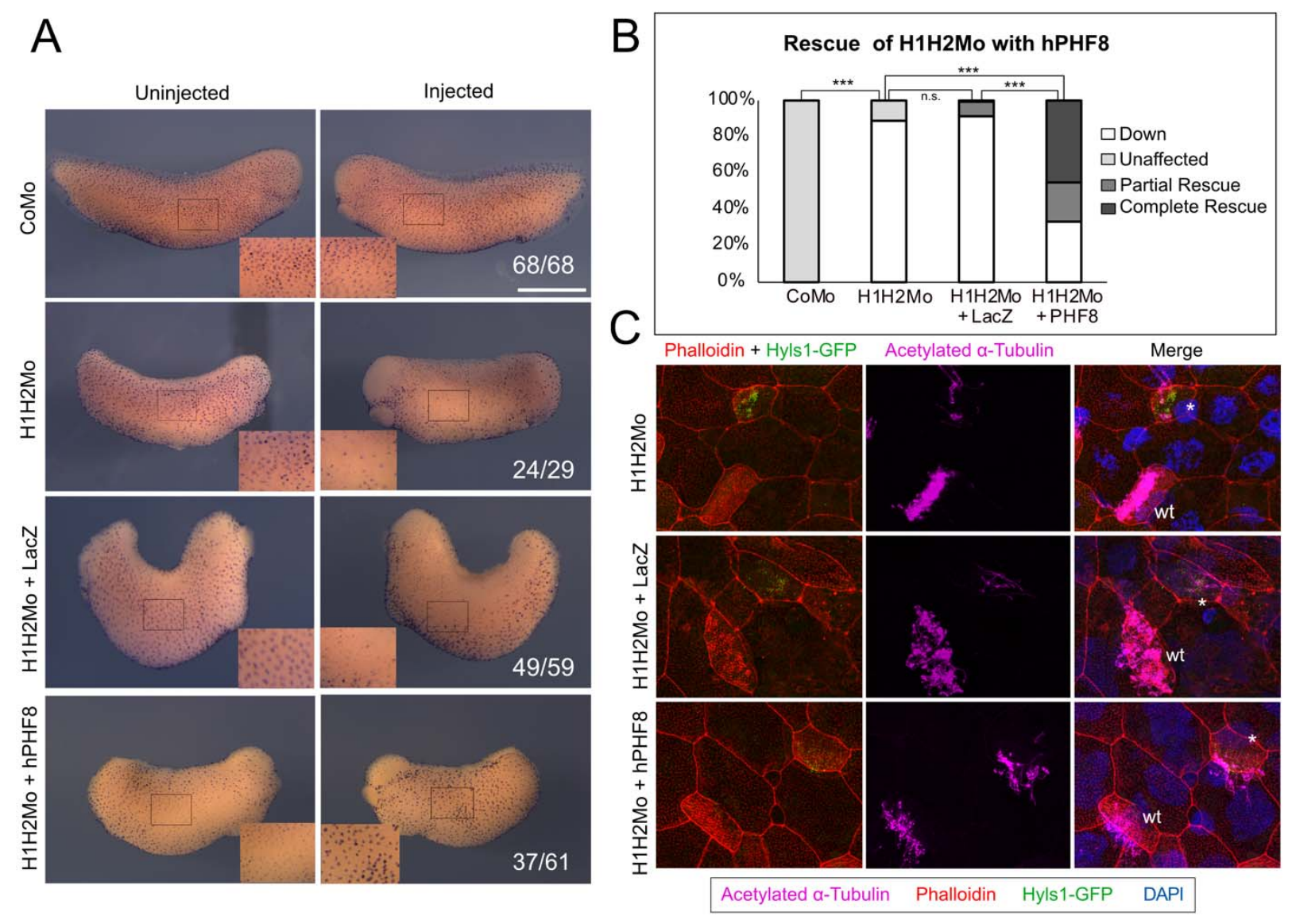


bioRxiv preprint doi: https://doi.org/10.1101/2020.12.01.404053; this version posted December 2, 2020. The copyright holder for this preprint (which was not certified by peer review) is the author/funder, who has granted bioRxiv a license to display the preprint in perpetuity. It is made available under aCC-BY 4.0 International license.

Figure 4

A Cilium genes (down in $\mathrm{H} 1 \mathrm{H} 2 \mathrm{Mo}$ vs. CoMo) $\square$ Improved in hPHF8 Rescue - hPHF8 Alone $\square$ Further down in hPHF8 Rescue - hPHF8 Alone

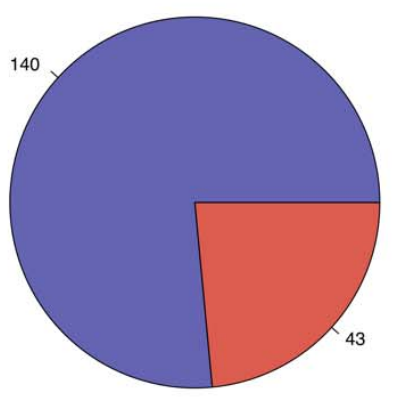

C

Cytoskeleton genes (down in $\mathrm{H} 1 \mathrm{H} 2 \mathrm{Mo}$ vs. CoMo)

Improved in hPHF8 Rescue - hPHF8 Alone $\square$ Further down in hPHF8 Rescue - hPHF8 Alone

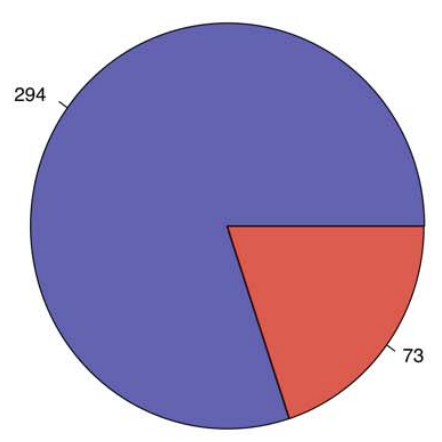

B

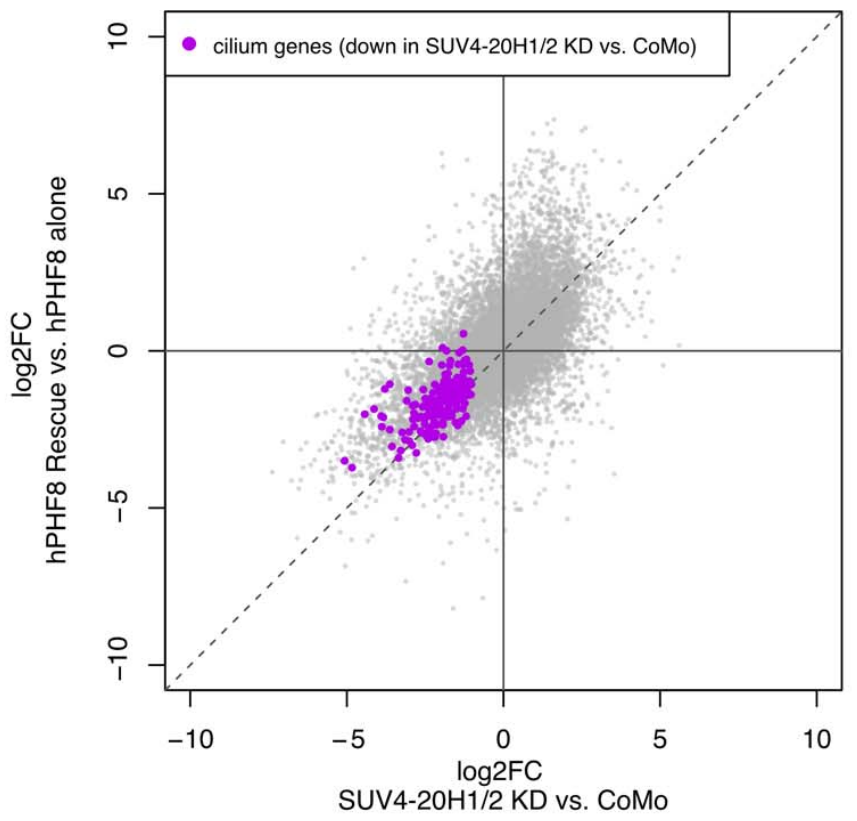

D

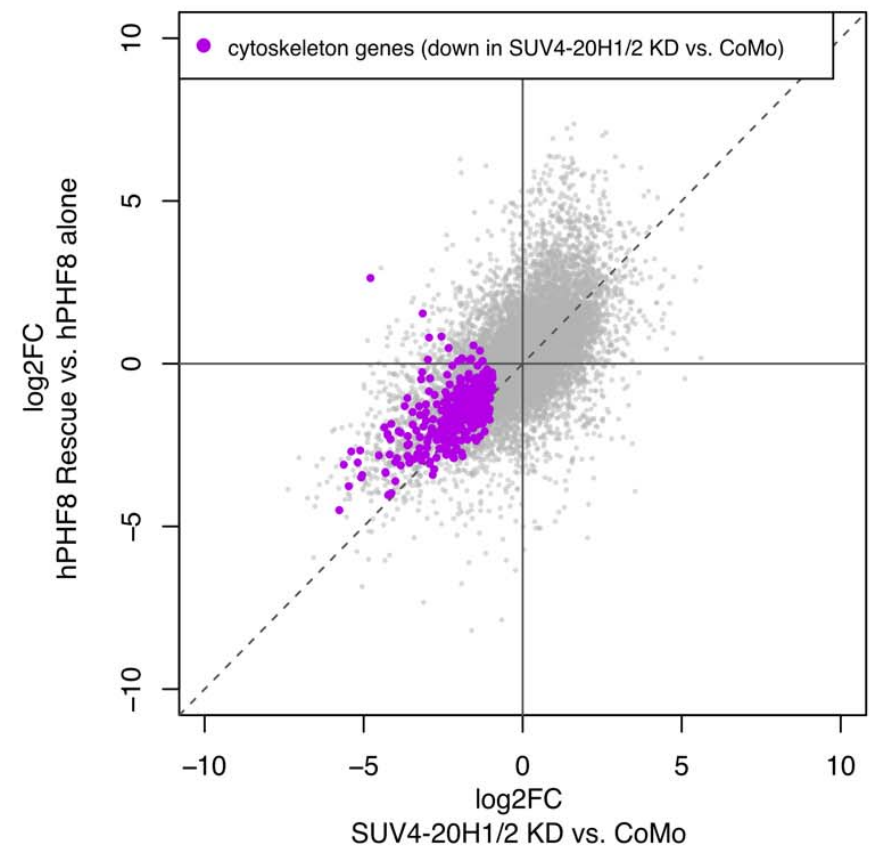


bioRxiv preprint doi: https://doi.org/10.1101/2020.12 01.404053; this version posted December 2, 2020. The copyright holder for this preprint (which was not certified by peer review) is the author/funder, who has granted bioRxiv a license to display the preprint in perpetuity. It is made available under aCC-BY 4.0 International license.

Figure 5
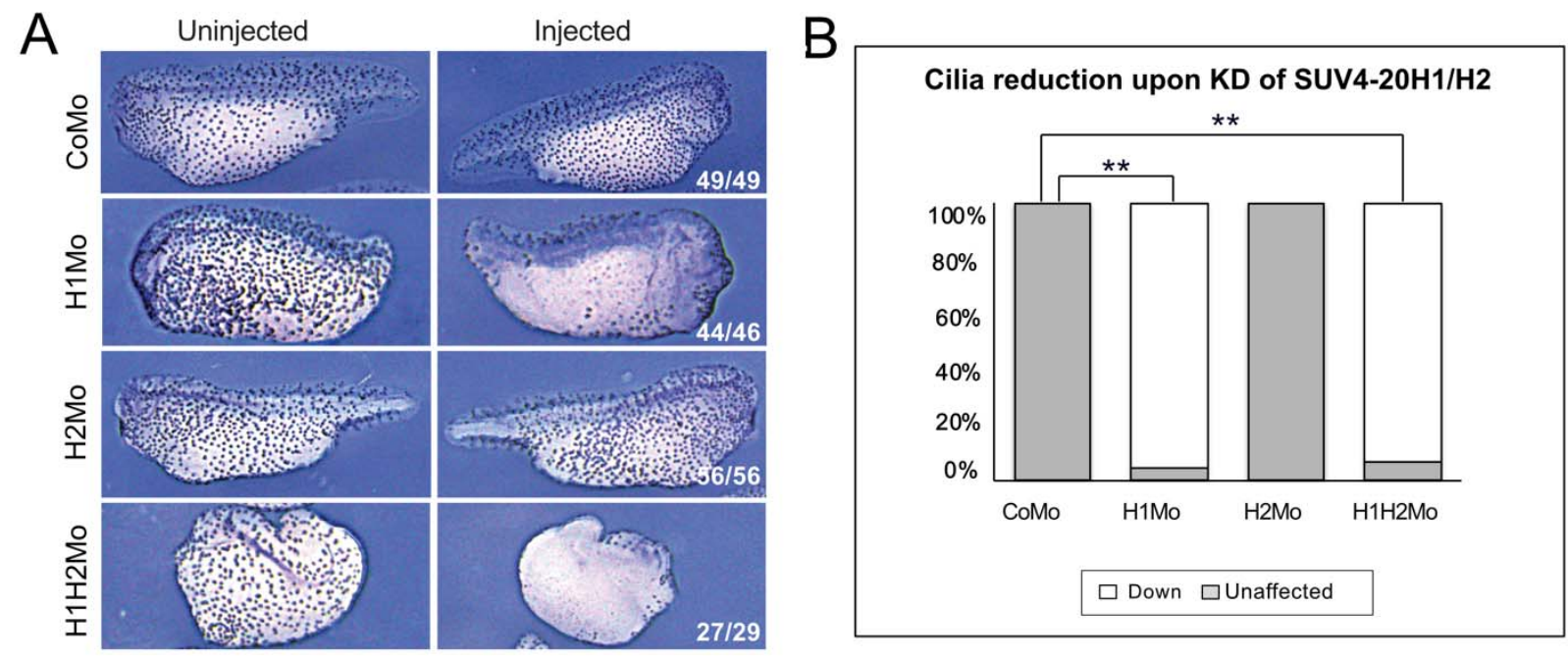

C

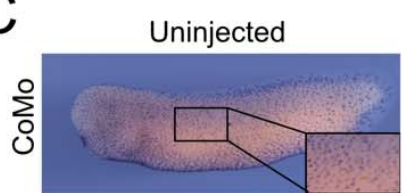

Injected
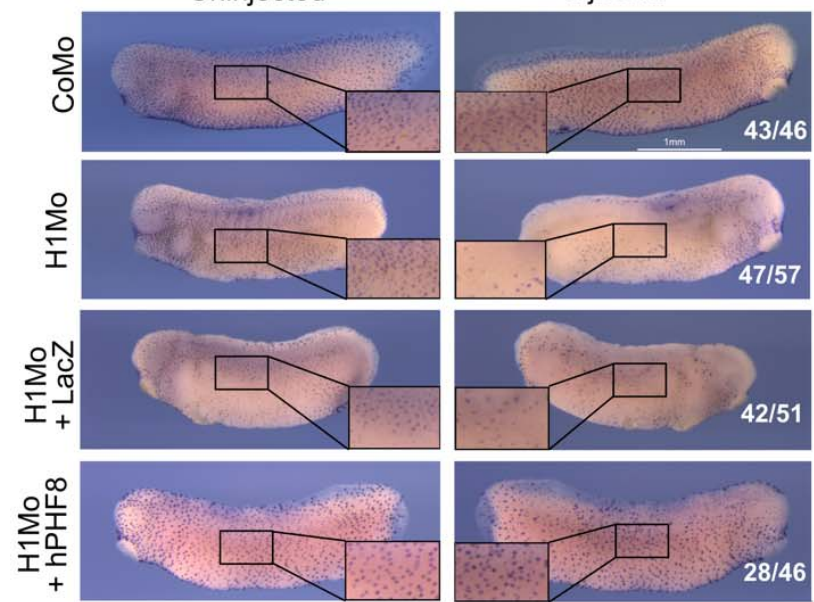

D

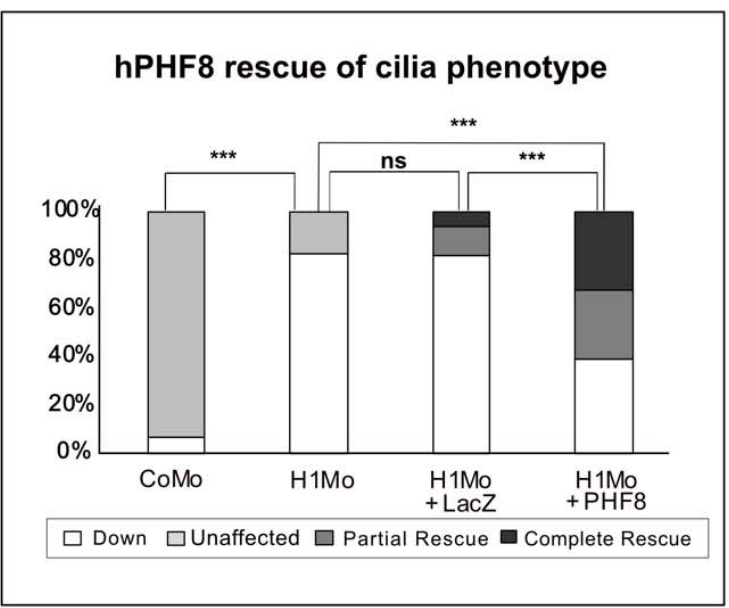

$E$

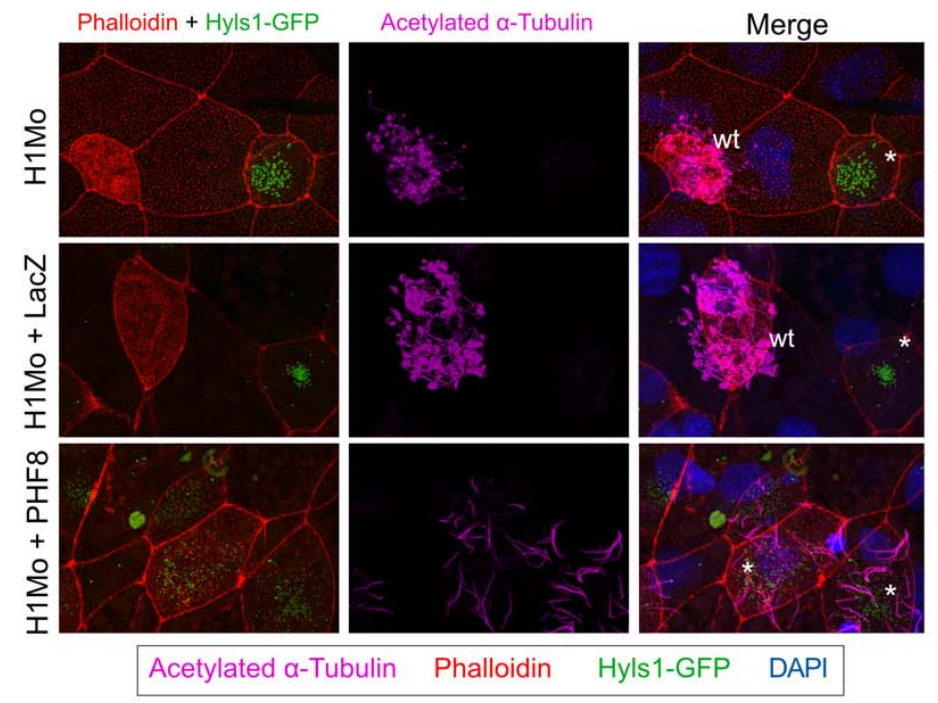


bioRxiv preprint doi: https://doi. org/10.1101/202012 01.404053. this version posted December 2 2020. The copyright holder for this preprint (which was not certified by peer review) is the author/funder, who has granted bioRxiv a license to display the preprint in perpetuity. It is made available under aCC-BY 4.0 International license.

Figure 6

A
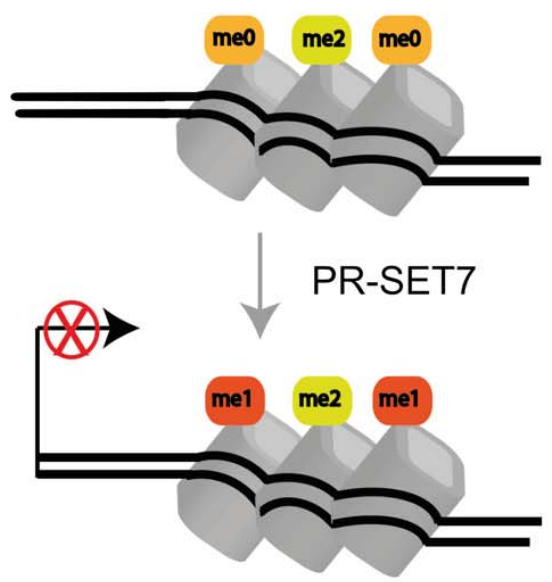

G2-M

Genomewide

$\mathrm{B}$
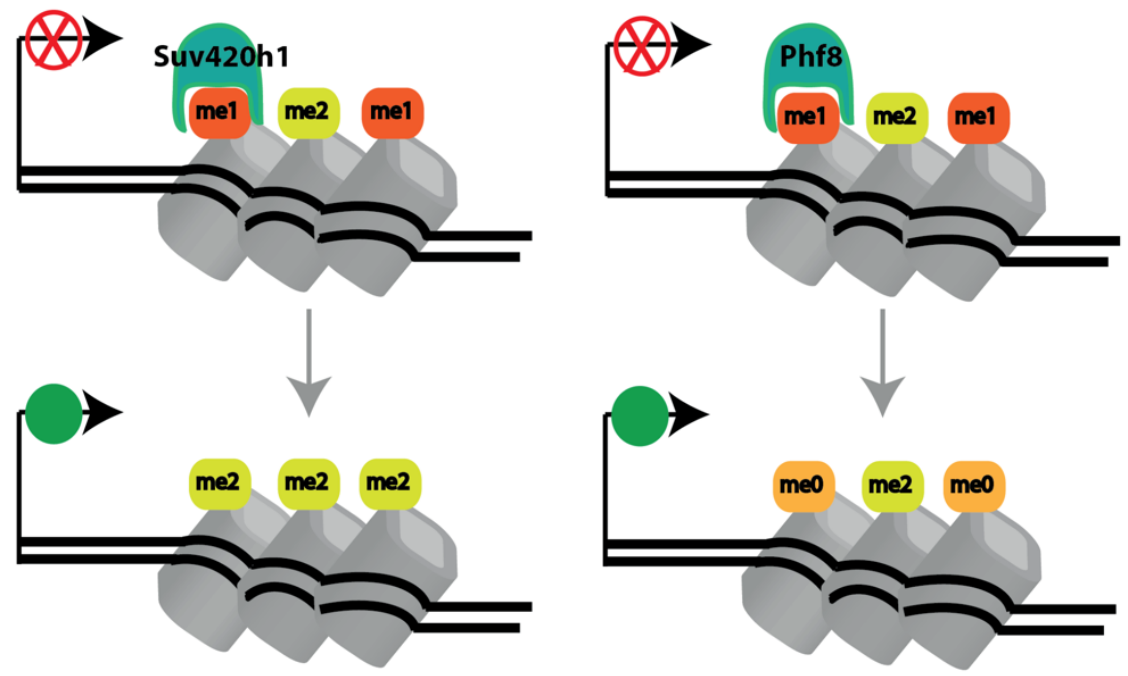

G1/G0

Genomewide/ specific loci 


\section{Supplementary Figures}

\section{Figure S1}

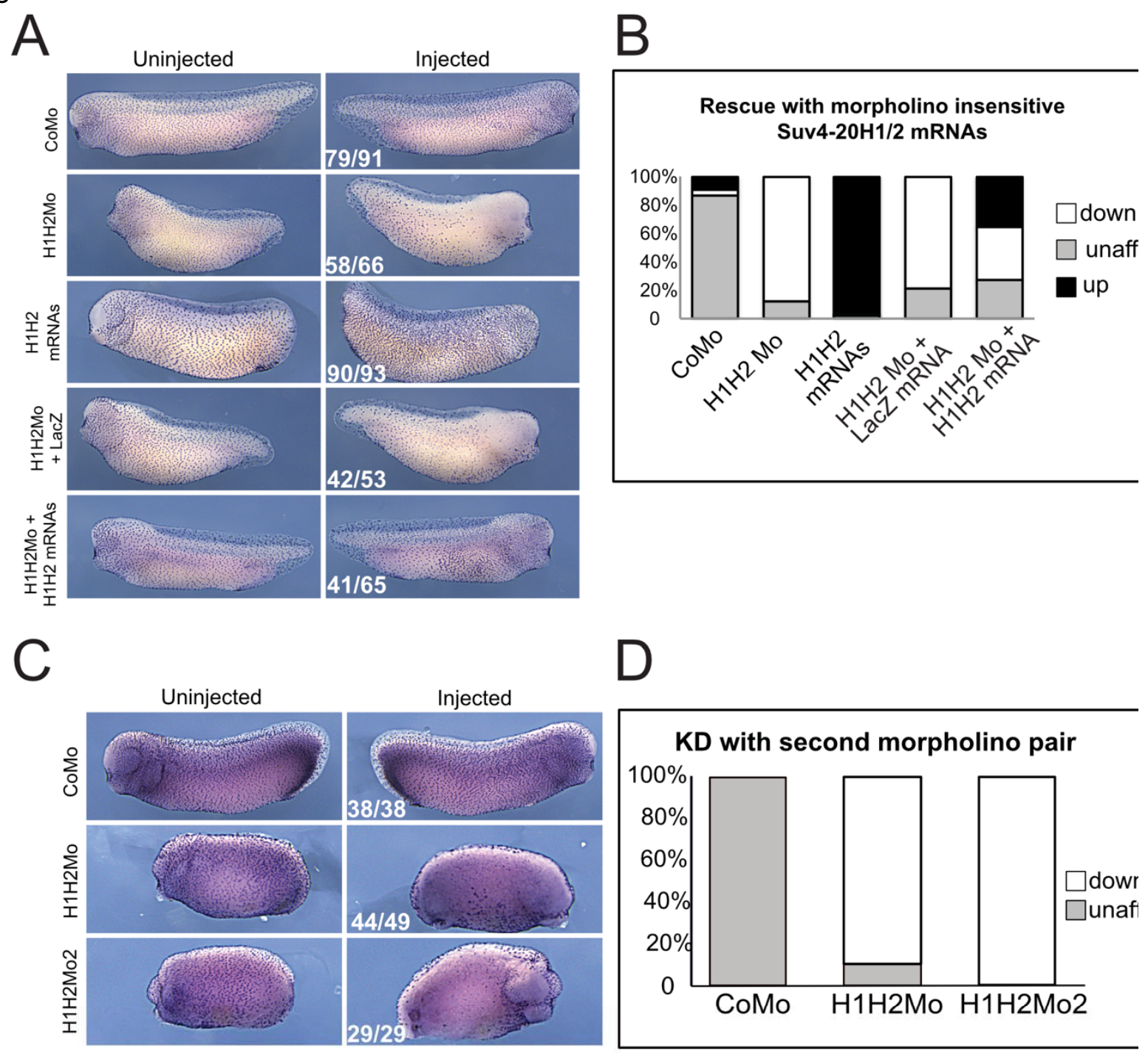

$\mathrm{E}$

\begin{tabular}{|c|c|}
\hline Suv4-20H1 & \\
\hline TCAGAGGGTGACTAAATGCAACTAGGTCAGA & TTGGCATGAAGTGGTTGGGCGAATCCAAG \\
\hline \begin{tabular}{|l} 
TCCCACTGATTTACGTTGATCCAGT \\
\end{tabular} & ACCGTACTTCACCAACCCGCTTAGG \\
\hline Suv4-20H2 & \\
\hline GAACTGTTGGGCGGAACAGCATGGTCGAAAG & ATACTATGGGTTCAAATCGCTTGACGGCCAGA \\
\hline AACCCGCCTTGTCGTACCAGCTTT & TACCCAAGTTTAGCCAACTGCCGTT \\
\hline Primary Morpholino (H1H2Mo) & Morpholino $(\mathrm{H} 1 \mathrm{H} 2 \mathrm{Mo}){ }^{2} \square$ Start Codon \\
\hline
\end{tabular}


bioRxiv preprint doi: https://doi.org/10.1101/2020.12.01.404053; this version posted December 2, 2020. The copyright holder for this preprint (which was not certified by peer review) is the author/funder, who has granted bioRxiv a license to display the preprint in perpetuity. It is made available under aCC-BY 4.0 International license.

\section{Figure S2}
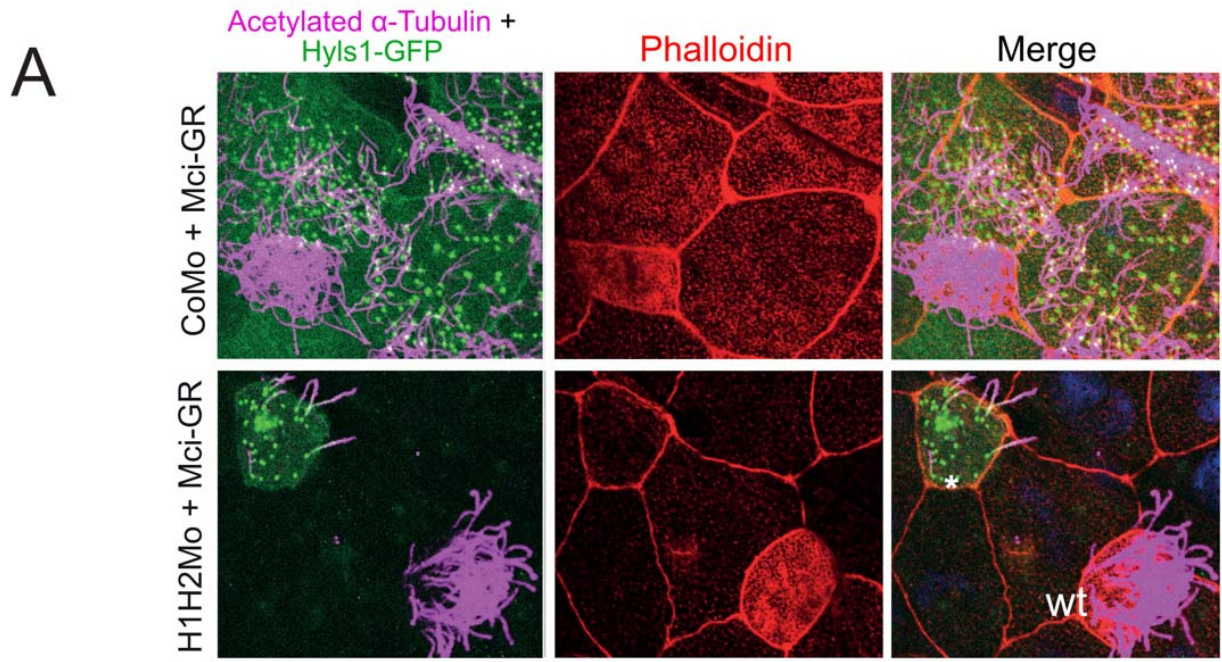

B
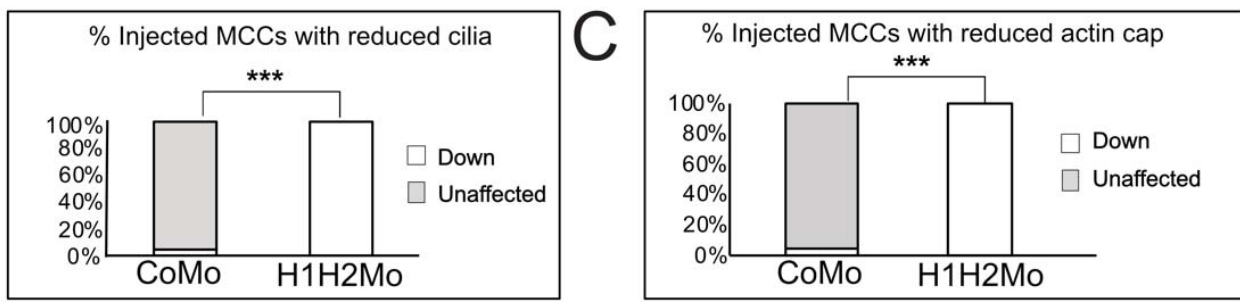

Acetylated $\alpha$-Tubulin +
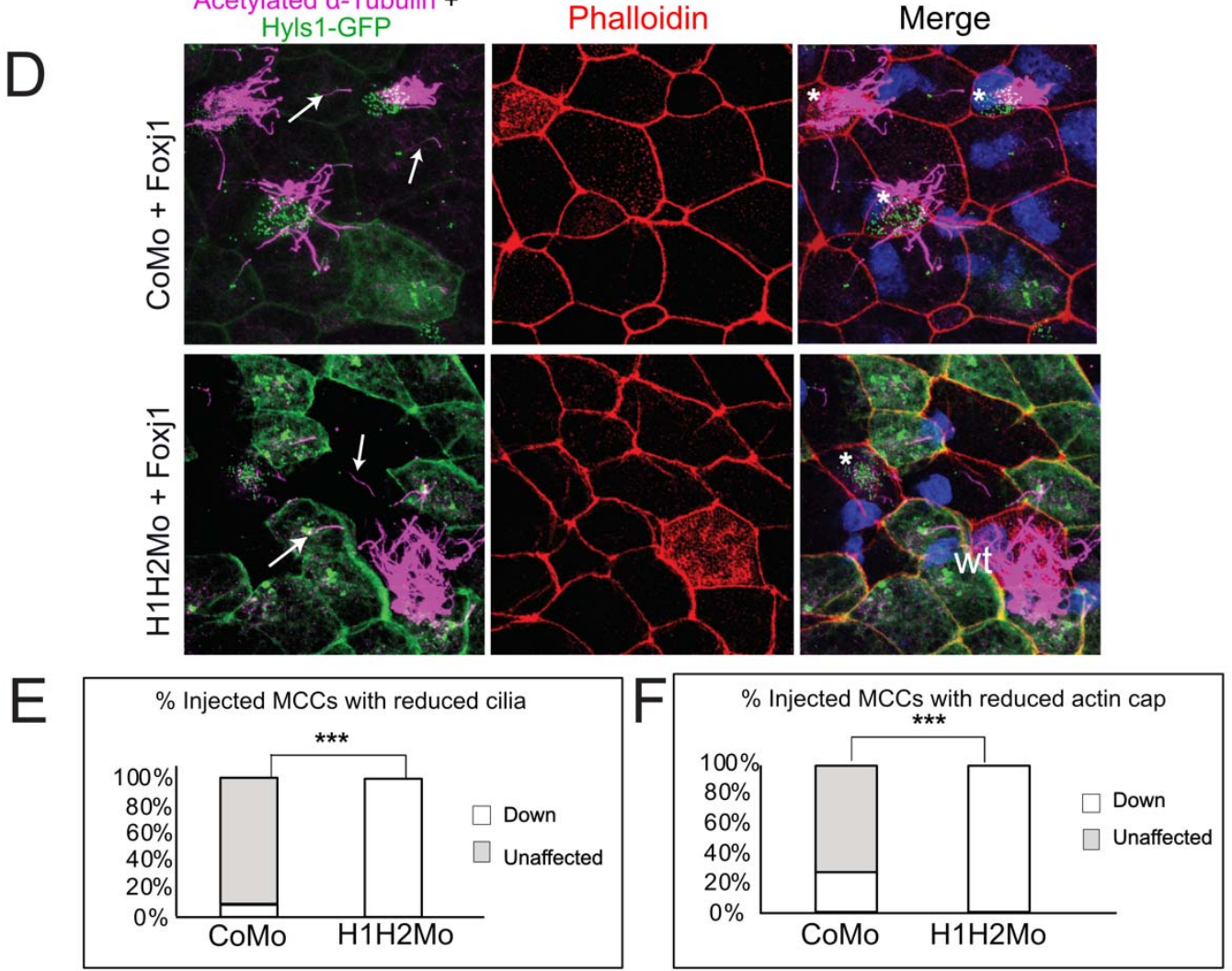
bioRxiv preprint doi: https://doi.org/10.1101/2020.12.01.404053; this version posted December 2, 2020. The copyright holder for this preprint (which was not certified by peer review) is the author/funder, who has granted bioRxiv a license to display the preprint in perpetuity. It is made available under aCC-BY 4.0 International license.

Figure S3
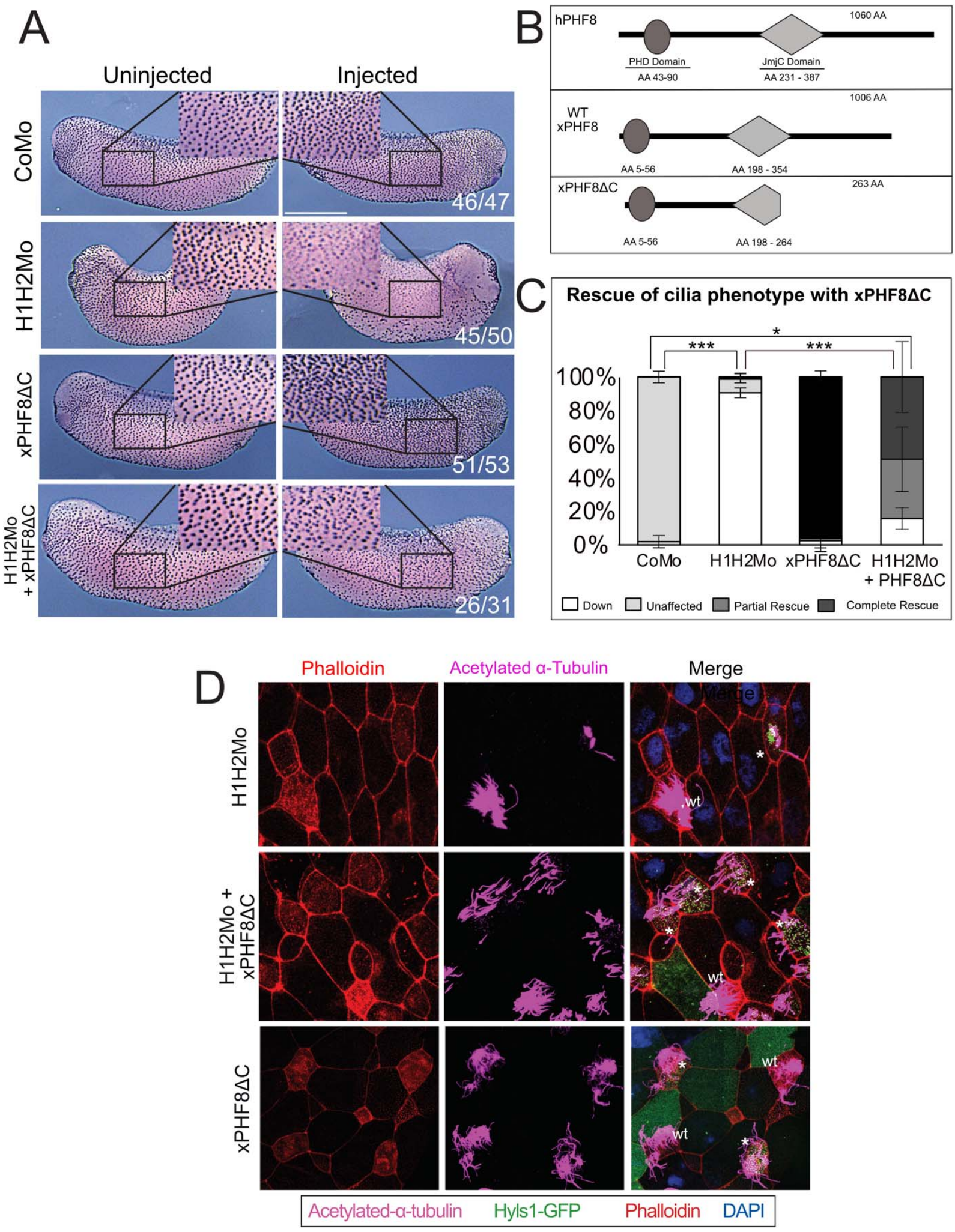
bioRxiv preprint doi: https://doi. org/10.1101/2020.12.01.404053; this version posted December 2, 2020. The copyright holder for this preprint (which was not certified by peer review) is the author/funder, who has granted bioRxiv a license to display the preprint in perpetuity. It is made available under aCC-BY 4.0 International license.

\section{Figure S4}

A Improved in xPHF8 $\triangle$ C Rescue-xPHF8 $\triangle \mathrm{C}$ alone
$\square$ Further Down in xPHF8 $\triangle$ C Rescue-xPHF8 $\triangle \mathrm{C}$ alone

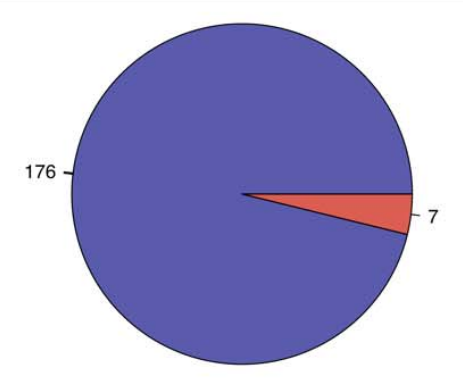

C

Cytoskeleton genes (down in H1H2Mo vs. CoMo)

I Improved in XPHF8 $\triangle \mathrm{C}$ Rescue-xPHF8 $\triangle \mathrm{C}$ alone

Further Down in XPHF8 $\triangle \mathrm{C}$ Rescue-xPHF8 $\triangle \mathrm{C}$ alone

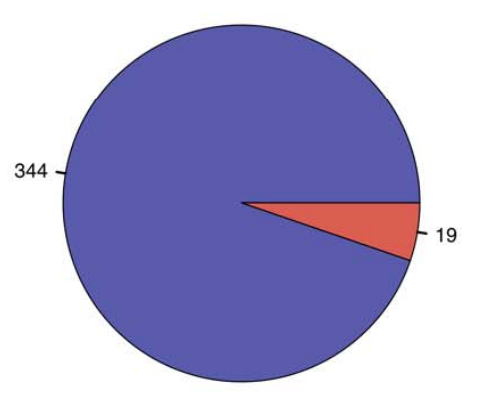

B

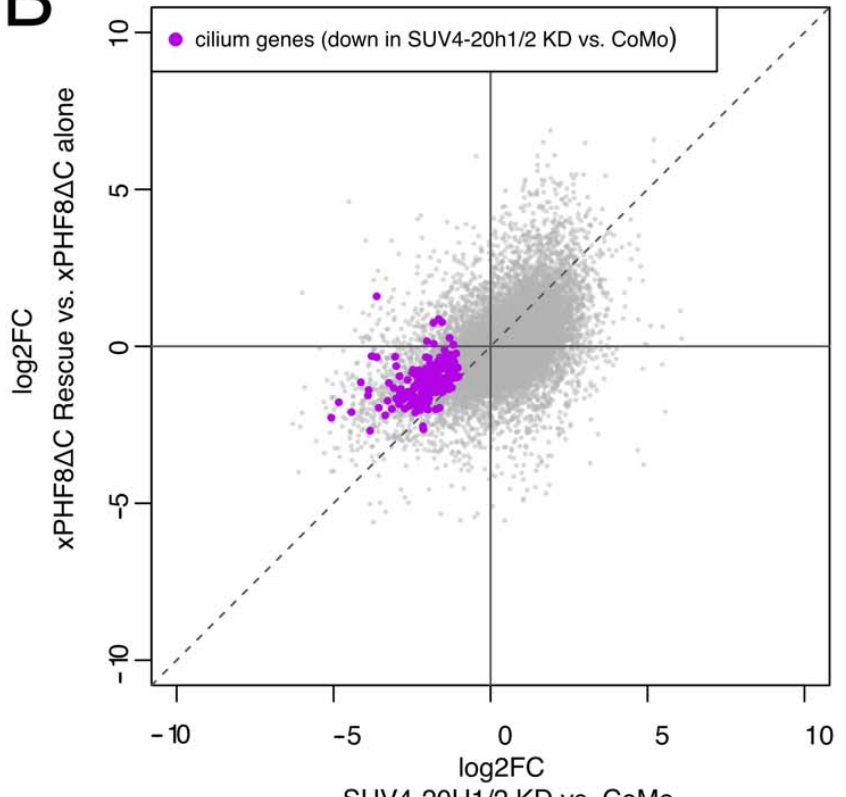

SUV4-20H1/2 KD vs. CoMo

$D$

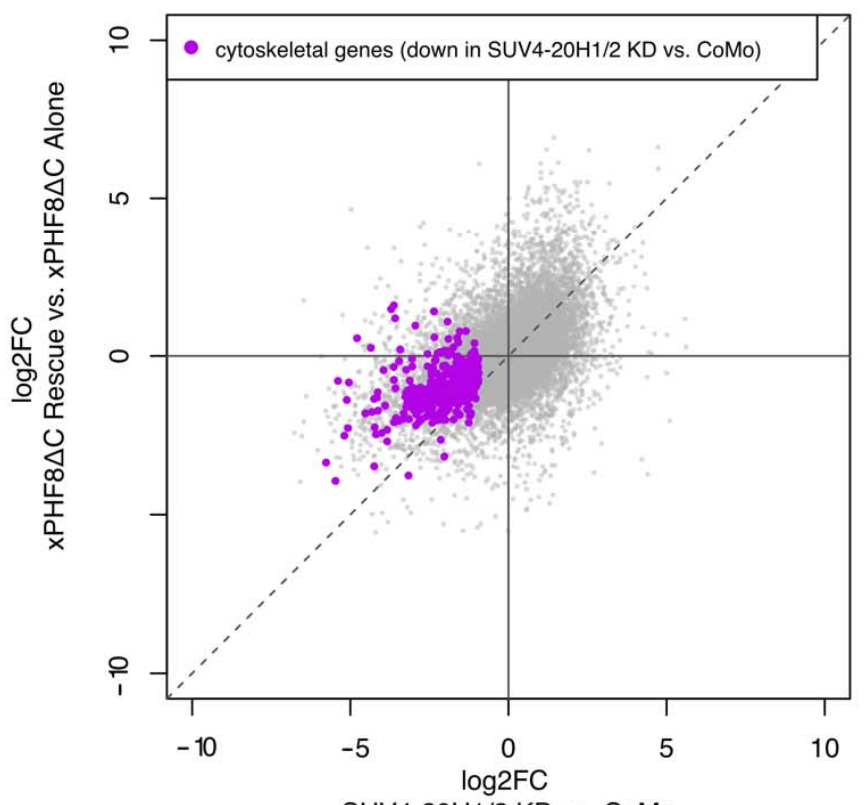

SUV4-20H1/2 KD vs. CoMo 